\title{
Identification of C3H2C3-type RING E3 ubiquitin ligase in grapevine and characterization of drought resistance function of $\mathrm{VyRCHC114}$
}

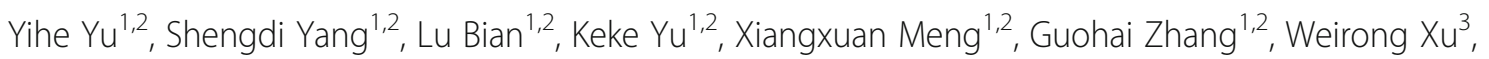
Wenkong Yao ${ }^{3}$ and Dalong Guo ${ }^{1,2^{*}}$

\begin{abstract}
Background: RING is one of the largest E3 ubiquitin ligase families and $\mathrm{C} 3 \mathrm{H} 2 \mathrm{C} 3$ type is the largest subfamily of RING, which plays an important role in plant growth and development, and growth and responses to biotic and abiotic stresses.

Results: A total of 143 RING C3H2C3-type genes (RCHCS) were discovered from the grapevine genome and separated into groups (I-XI) according to their phylogenetic analysis, and these genes named according to their positions on chromosomes. Gene replication analysis showed that tandem duplications play a predominant role in the expansion of VVRCHCs family together. Structural analysis showed that most VVRCHCs (67.13\%) had no more than 2 introns, while genes clustered together based on phylogenetic trees had similar motifs and evolutionarily conserved structures. Cis-acting element analysis showed the diversity of VVRCHCs regulation. The expression profiles of eight DEGs in RNA-Seq after drought stress were like the results of qRT-PCR analysis. In vitro ubiquitin experiment showed that VyRCHC114 had E3 ubiquitin ligase activity, overexpression of VyRCHC114 in Arabidopsis improved drought tolerance. Moreover, the transgenic plant survival rate increased by $30 \%$, accompanied by electrolyte leakage, chlorophyll content and the activities of SOD, POD, APX and CAT were changed. The quantitative expression of AtCOR15a, AtRD29A, AtERD15 and AtP5CS1 showed that they participated in the response to drought stress may be regulated by the expression of VyRCHC114.
\end{abstract}

Conclusions: This study provides valuable new information for the evolution of grapevine RCHCs and its relevance for studying the functional characteristics of grapevine VyRCHC114 genes under drought stress.

Keywords: RING, Drought stress, Grapevine, Ubiquitin, Overexpression

\footnotetext{
* Correspondence: guodalong@haust.edu.cn

${ }^{1}$ College of Horticulture and Plant Protection, Henan University of Science and Technology, Luoyang 471023, Henan Province, China

${ }^{2}$ Henan Engineering Technology Research Center of Quality Regulation and Controlling of Horticultural Plants, Luoyang 471023, Henan Province, China

Full list of author information is available at the end of the article
}

(C) The Author(s). 2021 Open Access This article is licensed under a Creative Commons Attribution 4.0 International License, which permits use, sharing, adaptation, distribution and reproduction in any medium or format, as long as you give appropriate credit to the original author(s) and the source, provide a link to the Creative Commons licence, and indicate if changes were made. The images or other third party material in this article are included in the article's Creative Commons licence, unless indicated otherwise in a credit line to the material. If material is not included in the article's Creative Commons licence and your intended use is not permitted by statutory regulation or exceeds the permitted use, you will need to obtain permission directly from the copyright holder. To view a copy of this licence, visit http://creativecommons.org/licenses/by/4.0/ The Creative Commons Public Domain Dedication waiver (http://creativecommons.org/publicdomain/zero/1.0/) applies to the data made available in this article, unless otherwise stated in a credit line to the data. 


\section{Background}

To survive in a changing environment, post-translational modification of proteins often occurs when plants perceive and transmit internal or external signals. The acetylation, methylation, phosphorylation, and ubiquitination of proteins are the main types of posttranslational modification, which play a key role in different plant development stages and plant-environment interactions. The process of classifying intracellular proteins under the action of a variety of special enzymes, and specifically modifying the screened target proteins, is called ubiquitination [1]. In eukaryotic cells, the ubiquitin sfigystem is complex and mainly involving ubiquitin (a small molecule protein), intact $26 \mathrm{~S}$ proteasome, ubiquitin-activating enzyme (E1), ubiquitin-binding enzyme (E2), and ubiquitin-ligase (E3) [2]. The inactivated ubiquitin-dependent ATP is first activated by E1 through the thioester bond formed between the C-terminal of ubiquitin and the cysteine residue of E1; then the ubiquitin signal connected to E1 is transferred to the acetylcysteine of E2. In the next step, the ubiquitin linked to E2 is transferred directly or indirectly to the lysine residue of the target protein via E3. It is noteworthy that E3 ubiquitin ligase is the main factor determining the binding of specific protein during ubiquitination process [3], it can repeatedly add ubiquitin to the substrate protein, so that the target protein is degraded by the $26 \mathrm{~S}$ protease [4].

E3 ubiquitin ligases can be divided into 9 categories based on specific conserved domains: RING, HECT, Ubox, F-box, cullin, BTB, DDB, RBX and SKP. RING E3 ligases protein has a conserved RING domain, which can provide residence sites for E2 and specific substrates and enable E2-bound ubiquitin molecules to transfer to the host protein, thus completing the ubiquitination process. In the RING domain, there are eight conserved amino acids (Cys or His) located in the center of the threedimensional protein structure, which can combine with two zinc ions to help stabilize the entire structure. According to the types of conserved amino acid sites, they are divided into different subfamily. Among them, RING $\mathrm{C} 3 \mathrm{H} 2 \mathrm{C} 3$ is the largest subfamily. The RING conserved domain sequence of this family member is Cys- $X 2-C y s-$ $X(9-39)$-Cys- $X(1-3)$-His- $X(2-3)$-His- $X 2$-Cys- $X(4-48)$ Cys- $X 2$-Cys, $X$ is any amino acid. In recent years, a growing number of studies have shown that the RING E3 ligase gene also figure prominently in abiotic stress responses of plants [5]. SpRing is a RING-type E3 ubiquitin ligase located in endoplasmic reticulum and participates in salt stress signal transmission in wild tomato variety Solanum pimpinellifolium 'PI365967'. In addition, SpRing is silenced by virus-induced gene silencing, resulting in increased sensitivity of wild tomato to salt stress. Overexpression of SpRing in Arabidopsis can improve its salt tolerance [6]. SDIR1 (SALT AND DROUGHT-INDUCED REALLY INTERESTING NEW GENE FINGER1) is a RING-type E3 ubiquitin ligase that regulates the salt stress response and ABA signaling in Arabidopsis by degrading the target protein SDIRIP1 (SDIR1-INTERACTING PROTEIN1). The downstream transcription factor ABI5 (ABA-INSENSITIVE5) is regulated by SDIRIP1, and overexpression of ABI5 increases salt tolerance [7]. The E3 ubiquitin ligase OsHTAS (Oryza sativa HEAT TOLERANCE AT SEEDLING STAGE) regulates the stomatal opening state of leaves by regulating ROS homeostasis, thus improving the basal heat resistance of leaves. It involves two pathways, ABAmediated [8]. In Arabidopsis, CHYR1 (CHYZINC-FINGERANDRINGPROTEIN1) encodes the RING-type E3 ubiquitin ligase which interacts with the related protein kinase KINASE2 (SnRK2) and can be phosphorylated by SnRK2.6 on its Thr-178 residues. When mediated by ABA, CHYR1 promotes the production of reactive oxygen species (ROS), stomatal closure, and drought tolerance in plants [9]. The capsicum annular E3 ubiquitin ligase, CaAIRF1 (Capsicum annuum ADIP1 INTERACTING RING FINGER PROTEIN1), can interact with protein phosphatase CaADIP1 and positively regulate ABA signaling pathway to improve drought tolerance [10]. In Zea mays, ZmXerico1 encodes a RING-type E3 ligase, which can regulate the stability of ABA8'-hydroxylase protein and thereby enable control of the dynamic balance of ABA, hence, expression of $Z m X$ ericol endows maize plants with ABA sensitivity and improves their water use efficiency under drought stress [11]. Furthermore, Arabidopsis AtAIRP1, AtAIRP2, AtAIRP3 and CaAIR1 jointly encode an E3 ubiquitin ligase, which regulates drought responses by regulating ABA signaling transduction, the expression of these genes increases ABA-mediated stomatal closure [12-15]. Collectively, the above studies show that E3 ligase plays a crucial role in response to abiotic stress.

Grapevine (Vitis vinifera L.) is a major cash crop, whose cultivated varieties have a total worldwide output of nearly 70 million tons of the fruit berries from more 7 million hectares of harvested land [16]. This plant is mainly grown to produce table grapes, fruit juices, and wine [17]. Most grapevine producing areas in the world incur seasonal droughts. According to global climate modeling, droughts will intensify in the near future. Drought can adversely affect the growth and development of grapevines, because under drought stress the concentration of cytokinin in grape stems decreases, vegetative and reproductive growth are inhibited [18]. When grapevines are in full bloom, drought stress will also affect the pollination process, which decreases the fruit setting rate and affects the size of the individual fruit berries produced [19]. With worsening water 
shortages, drought stress is likely to become a key factor impacting grapevine and wine production worldwide [20]. Therefore, it is of great significance to grapevine production and breeding to study the drought resistance of wild grapevine plants as this could uncover the molecular mechanisms enabling them to withstand drought effects. Vitis yeshanensis is a wild grapevine plant native to arid areas of China, whose morphological characteristics indicate adaptability to arid environments in many aspects [21]. Several studies have shown that wild Vitis yeshanensis has stronger drought resistance than other cultivars [22, 23].

The RING-type gene family has been found in more and more plant species, and its importance in plant stress responses and growth and development has been recognized, but RING-type genes have not been fully identified in grapevine. It is reported that the RING type E3 ubiquitin ligase is involved in grapevine stress and growth, but few studies have investigated the involvement of E3 ubiquitin ligase in regulating grapevine response to drought stress. We assume that $\mathrm{RCHC}$ protein may mediate the ubiquitination of key factors during grape drought stress to regulate plant drought resistance. This study aimed to characterize the RING-type E3 ubiquitin ligase in grapevine's genome and its relevance for drought stress. Genome-wide identification of $\mathrm{C} 3 \mathrm{H} 2 \mathrm{C} 3$ genes, the largest subfamily of grapevine RING-type, was carried out, coupled to their phylogenetic analysis, gene structure analysis, chromosome mapping, gene replication analysis, and cis-acting element analysis in gene promoter regions. We also quantified the expression levels of these genes under simulated drought treatment, 136 RCHC genes were found to be expressed and 52 DEGs, which 8 DEGs at least 3 stages. The $V y R C H C 114$ gene was confirmed by RT-qPCR, and then the ubiquitin ligase activity of the gene was verified. The function of the gene under drought conditions was elucidated using Arabidopsis transgenic plants. Our study provides an important basis for the involvement of $\mathrm{RCHC}$ protein in the regulation of grape ubiquitination under drought stress.

\section{Results}

\section{Genome-wide identification of RING $\mathrm{C} 3 \mathrm{H} 2 \mathrm{C} 3$ type finger} proteins in grapevine

The results of the Hidden Markov Model (HMM) were analyzed, and the gene sequences were extracted and given to SMART, CDD, and Pfam for domain authentication. From this, $143 \mathrm{VvRCHC}$ genes were obtained by comparing and screening genes with eight conservative metal ligands, and the alignment members were not abandoned. The physicochemical properties of 143 $V v R C H C s$ were identified (Table 1). The number of amino acids encoded by the $143 \mathrm{~V} v \mathrm{RCHCs}$ ranged from
$70(V v R C H C 50)$ to $763(V v R C H C 98)$. For these genes, the molecular weights of their products varied from $7.83 \mathrm{kDa}$ to $83.58 \mathrm{kDa}$, while their isoelectric points varied from 3.88 to 9.95 .

\section{Analysis of $V v R C H C s$ in the $\mathrm{C} 3 \mathrm{H} 2 \mathrm{C} 3$ domain}

The typical RING domain is considered to be an octahedral group of metal-bound cysteine and its residues, which can chelate two zinc ions in a spherical crosssupported structure, in which the metal ligands 1 and 3, 2 and 4, each bind to one zinc ion. This structure requires a certain distance between adjacent metal ligands, it being variable between $\mathrm{ml} 2 \sim \mathrm{ml} 3$ and $\mathrm{ml} 6 \sim \mathrm{ml} 7$. We calculated statistics for this distance between adjacent metal ligands (Table S2). It was found that, except those between $\mathrm{ml} 2 \sim \mathrm{ml} 3$ and $\mathrm{ml} 6 \sim \mathrm{ml} 7$, the distances between other metal ligands were constant, while those from $\mathrm{ml} 2$ to $\mathrm{ml} 3$ spanned 11 to 24 amino acids, and for $\mathrm{ml} 6 \sim \mathrm{ml} 7$ the distance varied from 8 to 14 amino acids. The $143 V v R C H C s$ C3H2C3 domains have two amino acids between $\mathrm{ml} 1 \sim \mathrm{ml} 2$ and $\mathrm{ml} 5 \sim \mathrm{ml}$, while $\mathrm{ml} 3 \sim$ ml4 contains one amino acid, $\mathrm{ml} 7 \sim \operatorname{ml} 8$ contains two amino acids as does $\mathrm{ml} 4 \sim \mathrm{ml} 5$. To understand whether these RING C3H2C3 structural domains are conserved apart from their eight special metal ligands, their comparative analysis was conducted (Fig. S1). This revealed that some amino acids in the structural domain of RING C3H2C3 have a typical position bias (Fig. 1a). In the $\mathrm{C} 3 \mathrm{H} 2 \mathrm{C} 3$ type RING region, the $\mathrm{ml} 2$ located in front of amino acid residues is the most common Ile (I) or Val $(\mathrm{V})$; likewise, the phenylalanine (Phe, F) residue is typically before $\mathrm{ml} 5$, the leucine residue (Leu, L) is always next to $\mathrm{ml} 2$, and the aspartic acid (Asp, D) residue is usually positioned after ml6, while the tryptophan residue (Trp, W) is usually the fourth following ml6. Notably, a very conservative proline $(\mathrm{P})$ was found situated after ml7. According to the RING-type $\mathrm{C} 3 \mathrm{H} 2 \mathrm{H} 3$ domain schematic diagram, two pairs of metal ligands bind to a zinc ion (Fig. 1b). The total amino acid length of the $\mathrm{C} 3 \mathrm{H} 2 \mathrm{C} 3$ domain per $V v R C H C$ gene and the corresponding number of different lengths were calculated: the vast majority of these were 41 and 42 , accounting for $88.8 \%$ of all genes (Fig. 1c).

\section{Phylogenetic analysis of $\mathrm{VvRCHCs}$}

To infer the evolutionary relationships of grapevine $V v R C H C s$, phylogenetic analysis of $\mathrm{RCHC}$ protein sequences of Arabidopsis, tomato, and grapevine were constructed (using the Maximum Likelihood method). According to the phylogenetic analysis, these 180 genes can be divided into 6 subgroups: I VI (Fig. 2). Group I has the least number of members, only 12 , and the group of the largest number of members is group III, 
Table 1 Detailed information of all 143 VvRCHCs identified in grapevine genome

\begin{tabular}{|c|c|c|c|c|c|c|}
\hline Gene name & Sequence ID & Chromosome & Localization & Protein Length $(a a)^{a}$ & Molecular Weight $(\mathrm{kDa})^{\mathrm{b}}$ & $p I^{c}$ \\
\hline$\overline{V V R C H C 1}$ & VIT_01s0011g00090.t01 & Chr1 & $116646 \sim 118695$ & 167 & 18.65 & 4.9 \\
\hline $\mathrm{V} V \mathrm{RCHC2}$ & VIT_01s0011g02350.t01 & Chr1 & 2131084 2131795 & 174 & 20.07 & 8.32 \\
\hline VVRCHC3 & VIT_01s0011g02360.t01 & Chr1 & 2136955 2137455 & 166 & 18.87 & 7.05 \\
\hline VVRCHC4 & VIT_01s0011g02380.t01 & Chr1 & $2145560 \sim 2145874$ & 104 & 12.09 & 5.06 \\
\hline VVRCHC5 & VIT_01s0011g02390.t01 & Chr1 & $2147401 \sim 2148062$ & 172 & 19.91 & 5.88 \\
\hline VVRCHC6 & VIT_01s0011g02410.t01 & Chr1 & 2170994 2171522 & 173 & 19.97 & 7.57 \\
\hline VVRCHC7 & VIT_01s0011g02420.t01 & Chr1 & 2187275 2187979 & 173 & 19.70 & 6.64 \\
\hline VVRCHC8 & VIT_01s0011g04080.t01 & Chr1 & $3727811 \sim 3730410$ & 351 & 38.67 & 9.46 \\
\hline VVRCHC9 & VIT_01s0026g00300.t01 & Chr1 & 8988327 8989738 & 420 & 45.76 & 6.01 \\
\hline VVRCHC10 & VIT_01s0026g02540.t01 & Chr1 & $12168327 \sim 12169146$ & 233 & 25.68 & 4.87 \\
\hline VVRCHC11 & VIT_01s0150g00260.t01 & Chr1 & $22675690 \sim 22682439$ & 232 & 25.76 & 5.25 \\
\hline VVRCHC12 & VIT_02s0025g00030.t01 & Chr2 & $209926 \sim 211750$ & 227 & 24.95 & 4.4 \\
\hline VVRCHC13 & VIT_02s0025g00140.t01 & Chr2 & 291046 291759 & 168 & 19.26 & 4.66 \\
\hline VVRCHC14 & VIT_02s0025g01430.t01 & Chr2 & 1379376 1383064 & 386 & 42.37 & 6.09 \\
\hline VVRCHC15 & VIT_02s0025g03070.t01 & Chr2 & $2622704 \sim 2623554$ & 187 & 20.18 & 5.72 \\
\hline VVRCHC16 & VIT_02s0025g04150.t01 & Chr2 & $3670653 \sim 3678402$ & 384 & 42.55 & 5.23 \\
\hline VVRCHC17 & VIT_02s0012g01440.t01 & Chr2 & $7633461 \sim 7635180$ & 292 & 33.14 & 4.96 \\
\hline VVRCHC18 & VIT_02s0087g00420.t01 & Chr2 & $17748161 \sim 17758528$ & 561 & 62.51 & 8.15 \\
\hline VVRCHC19 & VIT_03s0063g00160.t01 & Chr3 & $3768331 \sim 3782384$ & 734 & 78.34 & 6.06 \\
\hline VVRCHC2O & VIT_03s0063g01890.t01 & Chr3 & 5217040 5219107 & 396 & 45.16 & 9.95 \\
\hline VVRCHC21 & VIT_03s0091g00480.t01 & Chr3 & $6851584 \sim 6855075$ & 278 & 31.25 & 8.63 \\
\hline VVRCHC22 & VIT_03s0088g00930.t01 & Chr3 & 9146189 9147403 & 393 & 42.59 & 6.53 \\
\hline VVRCHC23 & VIT_03s0088g01090.t01 & Chr3 & $9340156 \sim 9341562$ & 457 & 49.83 & 6.71 \\
\hline VVRCHC24 & VIT_03s0097g00680.t01 & Chr3 & $11239802 \sim 11241097$ & 421 & 45.90 & 6.41 \\
\hline VVRCHC25 & VIT_03s0017g00670.t01 & Chr3 & 15529867 15532640 & 427 & 47.50 & 5.43 \\
\hline VVRCHC26 & VIT_04s0008g02290.t01 & Chr4 & 1889354 1891807 & 293 & 32.81 & 5.02 \\
\hline VVRCHC27 & VIT_04s0008g02390.t01 & Chr4 & 1970602 1975816 & 550 & 60.01 & 8.19 \\
\hline VVRCHC28 & VIT_04s0008g04280.t01 & Chr4 & $3660980 \sim 3669030$ & 401 & 44.19 & 7.88 \\
\hline VVRCHC29 & VIT_04s0008g04480.t01 & Chr4 & $3852636 \sim 3861794$ & 315 & 36.68 & 7.19 \\
\hline VVRCHC30 & VIT_04s0023g03460.t01 & Chr4 & 20022053 20022628 & 166 & 18.05 & 6.97 \\
\hline VVRCHC31 & VIT_05s0077g01970.t01 & Chr5 & 1538565 1539938 & 317 & 34.99 & 8.34 \\
\hline VVRCHC32 & VIT_05s0020g01800.t01 & Chr 5 & $3519576 \sim 3525991$ & 267 & 31.02 & 6.58 \\
\hline VVRCHC33 & VIT_05s0020g04000.t01 & Chr5 & $5689012 \sim 5690195$ & 164 & 18.50 & 9.8 \\
\hline VVRCHC34 & VIT_05s0049g00480.t01 & Chr5 & 7527982 7529676 & 390 & 43.91 & 8.25 \\
\hline VVRCHC35 & VIT_05s0051g00730.t01 & Chr5 & 11700888 11720325 & 190 & 21.26 & 6.14 \\
\hline VVRCHC36 & VIT_06s0004g00120.t01 & Chr6 & $257501 \sim 259353$ & 368 & 40.90 & 4.82 \\
\hline VVRCHC37 & VIT_06s0004g01930.t01 & Chr6 & $2373671 \sim 2382922$ & 252 & 28.69 & 5.47 \\
\hline VVRCHC38 & VIT_06s0004g05080.t01 & Chr6 & $6014664 \sim 6018771$ & 284 & 31.83 & 5.73 \\
\hline VVRCHC39 & VIT_06s0004g05090.t01 & Chr6 & $6020330 \sim 6022057$ & 386 & 42.57 & 8.87 \\
\hline VVRCHC4O & VIT_06s0004g06930.t01 & Chr6 & $7643002 \sim 7643805$ & 267 & 29.33 & 5.76 \\
\hline VVRCHC41 & VIT_06s0004g08080.t01 & Chr6 & 8843648 8845413 & 263 & 29.12 & 7.89 \\
\hline VVRCHC42 & VIT_06s0009g02350.t01 & Chr6 & 14742953 14747814 & 336 & 36.99 & 6.3 \\
\hline VVRCHC43 & VIT_06s0009g03540.t01 & Chr6 & 16816009 16816598 & 162 & 18.43 & 5.32 \\
\hline VVRCHC44 & VIT_06s0061g00710.t01 & Chr6 & 18243947 18247168 & 289 & 33.05 & 6.45 \\
\hline
\end{tabular}


Table 1 Detailed information of all 143 VvRCHCs identified in grapevine genome (Continued)

\begin{tabular}{|c|c|c|c|c|c|c|}
\hline Gene name & Sequence ID & Chromosome & Localization & Protein Length $(a a)^{\mathrm{a}}$ & Molecular Weight $(\mathrm{kDa})^{\mathbf{b}}$ & $p l^{c}$ \\
\hline VVRCHC45 & VIT_07s0104g01370.t01 & Chr7 & 2388448 2393119 & 268 & 31.42 & 6.1 \\
\hline VVRCHC46 & VIT_07s0005g00710.t01 & Chr7 & $3351600 \sim 3352612$ & 263 & 28.82 & 6.7 \\
\hline VVRCHC47 & VIT_07s0005g03120.t01 & Chr7 & $5941893 \sim 5942809$ & 264 & 29.97 & 6.11 \\
\hline VVRCHC48 & VIT_07s0191g00230.t01 & Chr7 & 15035569 15037412 & 372 & 41.30 & 5.98 \\
\hline VVRCHC49 & VIT_07s0031g00370.t01 & Chr7 & $16601231 \sim 16602190$ & 145 & 16.55 & 4.66 \\
\hline VVRCHC50 & VIT_07s0031g00380.t01 & Chr7 & 16612579 16612919 & 70 & 7.83 & 4.93 \\
\hline VVRCHC51 & VIT_07s0031g00390.t01 & Chr7 & $16615612 \sim 16618016$ & 244 & 26.72 & 4.48 \\
\hline VVRCHC52 & VIT_07s0031g00400.t01 & Chr7 & $16623222 \sim 16623766$ & 102 & 11.17 & 4.45 \\
\hline VVRCHC53 & VIT_07s0031g00440.t01 & Chr7 & $16651426 \sim 16652337$ & 220 & 24.25 & 4.17 \\
\hline VVRCHC54 & VIT_07s0031g01270.t01 & Chr7 & $17354201 \sim 17354899$ & 159 & 18.65 & 5.95 \\
\hline VVRCHC55 & VIT_07s0031g02250.t01 & Chr7 & 18383520 18384391 & 182 & 19.29 & 8.32 \\
\hline VVRCHC56 & VIT_08s0056g00320.t01 & Chr8 & 453669 461038 & 590 & 66.55 & 4.63 \\
\hline VVRCHC57 & VIT_08s0058g01270.t01 & Chr8 & $10736680 \sim 10737686$ & 195 & 21.19 & 6.91 \\
\hline VVRCHC58 & VIT_08s0040g00310.t01 & Chr8 & $11231370 \sim 11255659$ & 385 & 43.10 & 6.81 \\
\hline VVRCHC59 & VIT_08s0040g00590.t01 & Chr8 & $11540810 \sim 11542129$ & 314 & 34.85 & 7.7 \\
\hline VVRCHC6O & VIT_08s0040g02160.t01 & Chr8 & $13268900 \sim 13272455$ & 546 & 60.42 & 6.26 \\
\hline VVRCHC61 & VIT_08s0040g02950.t01 & Chr8 & 13968494 13969465 & 285 & 31.37 & 7.6 \\
\hline VVRCHC62 & VIT_08s0007g00150.t01 & Chr8 & 14536064 14536944 & 178 & 19.87 & 5.78 \\
\hline VVRCHC63 & VIT_08s0007g00720.t01 & Chr8 & $14916670 \sim 14922764$ & 516 & 57.58 & 8.62 \\
\hline VVRCHC64 & VIT_08s0007g04790.t01 & Chr8 & 18767623 18771322 & 289 & 33.33 & 6.11 \\
\hline VVRCHC65 & VIT_09s0002g00220.t01 & Chr9 & $197510 \sim 198755$ & 304 & 33.08 & 5.68 \\
\hline VVRCHC66 & VIT_09s0002g01500.t01 & Chr9 & $1282580 \sim 1283385$ & 140 & 15.83 & 4.92 \\
\hline VVRCHC67 & VIT_09s0002g05120.t01 & Chr9 & $4813804 \sim 4820015$ & 442 & 48.81 & 6.5 \\
\hline VVRCHC68 & VIT_09s0002g05130.t01 & Chr9 & $4821806 \sim 4822755$ & 208 & 22.69 & 5.82 \\
\hline VVRCHC69 & VIT_09s0002g05140.t01 & Chr9 & $4836806 \sim 4838491$ & 309 & 33.91 & 5.16 \\
\hline VVRCHC7O & VIT_10s0003g00850.t01 & Chr10 & $2100756 \sim 2101775$ & 218 & 23.74 & 5.19 \\
\hline VVRCHC71 & VIT_10s0042g00580.t01 & Chr10 & $13534118 \sim 13544150$ & 308 & 33.77 & 3.88 \\
\hline VVRCHC72 & VIT_11s0016g00070.t01 & Chr11 & $37814 \sim 38430$ & 136 & 15.38 & 8.71 \\
\hline VVRCHC73 & VIT_11s0016g01430.t01 & Chr11 & $1146136 \sim 1146786$ & 178 & 20.16 & 6.38 \\
\hline VVRCHC74 & VIT_11s0016g03190.t01 & Chr11 & 2563204 2564128 & 168 & 17.85 & 6.39 \\
\hline VVRCHC75 & VIT_11s0016g03420.t01 & Chr11 & 2778391 2787457 & 469 & 53.37 & 7.24 \\
\hline VVRCHC76 & VIT_11s0016g04450.t01 & Chr11 & $3757897 \sim 3762458$ & 407 & 44.19 & 5.53 \\
\hline VVRCHC77 & VIT_11s0118g00640.t01 & Chr11 & 6397984 6398548 & 119 & 13.64 & 4.55 \\
\hline VVRCHC78 & VIT_11s0118g00760.t01 & Chr11 & $6533770 \sim 6542103$ & 542 & 58.69 & 5.35 \\
\hline VVRCHC79 & VIT_11s0118g00780.t01 & Chr11 & $6552717 \sim 6553829$ & 193 & 21.59 & 9.37 \\
\hline VVRCHC8O & VIT_11s0037g01400.t01 & Chr11 & $10944676 \sim 10946544$ & 543 & 59.50 & 6.26 \\
\hline VVRCHC81 & VIT_11s0065g01210.t01 & Chr11 & 15329284 15329979 & 167 & 18.78 & 8.82 \\
\hline VVRCHC82 & VIT_11s0052g00360.t01 & Chr11 & $17683751 \sim 17684146$ & 131 & 14.89 & 4.83 \\
\hline VVRCHC83 & VIT_11s0052g00530.t01 & Chr11 & $17936593 \sim 17938168$ & 457 & 51.48 & 9.56 \\
\hline VVRCHC84 & VIT_12s0028g01220.t01 & Chr12 & 1843979 1851603 & 219 & 24.66 & 4.88 \\
\hline VVRCHC85 & VIT_12s0028g01560.t01 & Chr12 & $2265770 \sim 2266849$ & 190 & 22.29 & 8.77 \\
\hline VVRCHC86 & VIT_12s0028g01570.t01 & Chr12 & 2274491 2275931 & 224 & 26.20 & 7.62 \\
\hline VVRCHC87 & VIT_12s0028g01580.t01 & Chr12 & $2278915 \sim 2280538$ & 339 & 38.82 & 6.63 \\
\hline VVRCHC88 & VIT_12s0028g02530.t01 & Chr12 & $3292336 \sim 3293351$ & 254 & 27.54 & 5.72 \\
\hline
\end{tabular}


Table 1 Detailed information of all 143 VvRCHCs identified in grapevine genome (Continued)

\begin{tabular}{|c|c|c|c|c|c|c|}
\hline Gene name & Sequence ID & Chromosome & Localization & Protein Length $(a a)^{a}$ & Molecular Weight $(\mathrm{kDa})^{\mathrm{b}}$ & $p l^{c}$ \\
\hline$\overline{V V R C H C 89}$ & VIT_12s0028g03410.t01 & Chr12 & $4186053 \sim 4209365$ & 570 & 65.51 & 8.3 \\
\hline VVRCHC9O & VIT_12s0057g01330.t01 & Chr12 & 10069923 10070893 & 202 & 22.49 & 5.85 \\
\hline VVRCHC91 & VIT_12s0034g01390.t01 & Chr12 & $17398801 \sim 17400234$ & 451 & 52.26 & 8.22 \\
\hline VVRCHC92 & VIT_12s0034g01400.t01 & Chr12 & 17414404 17415189 & 261 & 29.71 & 6.86 \\
\hline VVRCHC93 & VIT_13s0067g02880.t01 & Chr13 & 1558971 1559978 & 197 & 21.06 & 6.73 \\
\hline VVRCHC94 & VIT_13s0019g00990.t01 & Chr13 & 2740552 2741055 & 167 & 18.34 & 5.94 \\
\hline VVRCHC95 & VIT_13s0019g01000.t01 & Chr13 & $2742040 \sim 2742492$ & 150 & 16.69 & 4.64 \\
\hline VVRCHC96 & VIT_13s0019g01020.t01 & Chr13 & 2749369 2749848 & 159 & 17.49 & 6.77 \\
\hline VVRCHC97 & VIT_13s0019g01960.t01 & Chr13 & $3261036 \sim 3269087$ & 275 & 30.08 & 6.23 \\
\hline VVRCHC98 & VIT_13s0019g01980.t01 & Chr13 & $3282264 \sim 3294013$ & 763 & 83.58 & 7.79 \\
\hline VVRCHC99 & VIT_13s0019g04100.t01 & Chr13 & 5376959 5389168 & 565 & 63.18 & 6.42 \\
\hline VVRCHC100 & VIT_13s0074g00370.t01 & Chr13 & $7973641 \sim 7981844$ & 209 & 23.54 & 5.82 \\
\hline VVRCHC101 & VIT_13s0084g00140.t01 & Chr13 & 18797445 18798197 & 191 & 20.08 & 7.57 \\
\hline VVRCHC102 & VIT_13s0064g01030.t01 & Chr13 & 22907333 22911899 & 247 & 28.32 & 5.45 \\
\hline VVRCHC103 & VIT_13s0156g00140.t01 & Chr13 & 23884150 23887948 & 312 & 33.41 & 4.7 \\
\hline VVRCHC104 & VIT_14s0060g00290.t01 & Chr14 & 278763 286055 & 137 & 16.21 & 7.58 \\
\hline VVRCHC105 & VIT_14s0128g00120.t01 & Chr14 & $2814506 \sim 2816124$ & 420 & 45.76 & 9.5 \\
\hline VVRCHC106 & VIT_14s0083g00710.t01 & Chr14 & 22855118 22856402 & 391 & 43.71 & 3.97 \\
\hline VVRCHC107 & VIT_14s0083g01000.t01 & Chr14 & 23286167 23293023 & 225 & 25.54 & 4.94 \\
\hline VVRCHC108 & VIT_14s0066g01610.t01 & Chr14 & 27970245 27971983 & 386 & 42.89 & 6.16 \\
\hline VVRCHC109 & VIT_15s0024g01990.t01 & Chr15 & $4356512 \sim 4356925$ & 137 & 14.73 & 5.93 \\
\hline VVRCHC110 & VIT_15s0045g00330.t01 & Chr15 & $5087898 \sim 5088931$ & 338 & 37.58 & 5.55 \\
\hline VVRCHC111 & VIT_15s0021g00890.t01 & Chr15 & 10761195 10763021 & 203 & 22.12 & 4.78 \\
\hline VVRCHC112 & VIT_15s0048g01840.t01 & Chr15 & 15988642 15991207 & 201 & 22.58 & 5.51 \\
\hline VVRCHC113 & VIT_15s0048g02030.t01 & Chr15 & $16165343 \sim 16170176$ & 382 & 43.09 & 5.65 \\
\hline VVRCHC114 & VIT_15s0046g00930.t01 & Chr15 & 17988199 17990082 & 372 & 40.71 & 4.78 \\
\hline VVRCHC115 & VIT_15s0046g01820.t01 & Chr15 & $18650570 \sim 18653922$ & 184 & 20.52 & 4.66 \\
\hline VVRCHC116 & VIT_15s0046g01880.t01 & Chr15 & 18703282 18703952 & 167 & 19.10 & 4.83 \\
\hline VVRCHC117 & VIT_15s0046g02070.t01 & Chr15 & 18873629 18874670 & 197 & 21.47 & 6.49 \\
\hline VVRCHC118 & VIT_15s0046g03770.t01 & Chr15 & 20300677 20302386 & 81 & 9.47 & 6.47 \\
\hline VVRCHC119 & VIT_16s0039g02200.t01 & Chr16 & 2285896 2293114 & 502 & 56.87 & 6.57 \\
\hline VVRCHC120 & VIT_16s0022g00290.t01 & Chr16 & $11163433 \sim 11164324$ & 76 & 8.64 & 7.57 \\
\hline VVRCHC121 & VIT_16s0022g00600.t01 & Chr16 & $11897657 \sim 11912487$ & 587 & 65.27 & 6.85 \\
\hline VVRCHC122 & VIT_16s0098g00250.t01 & Chr16 & 20642143 20644650 & 367 & 40.74 & 5.45 \\
\hline VVRCHC123 & VIT_17s0000g03210.t01 & Chr17 & $3094227 \sim 3100434$ & 371 & 40.80 & 8.7 \\
\hline VVRCHC124 & VIT_17s0000g04730.t01 & Chr17 & $5126163 \sim 5127854$ & 439 & 49.33 & 4.13 \\
\hline VVRCHC125 & VIT_17s0000g06460.t01 & Chr17 & 7045832 7050297 & 217 & 49.33 & 4.13 \\
\hline VVRCHC126 & VIT_17s0053g00320.t01 & Chr17 & 14868182 14869346 & 369 & 38.60 & 4.43 \\
\hline VVRCHC127 & VIT_18s0122g00870.t01 & Chr18 & $626783 \sim 627577$ & 184 & 19.24 & 8.28 \\
\hline VVRCHC128 & VIT_18s0001g01050.t01 & Chr18 & $1721216 \sim 1721614$ & 132 & 14.79 & 5.02 \\
\hline VVRCHC129 & VIT_18s0001g01060.t01 & Chr18 & $1727361 \sim 1728295$ & 114 & 12.33 & 4.84 \\
\hline VVRCHC130 & VIT_18s0001g02280.t01 & Chr18 & $2629486 \sim 2630245$ & 207 & 23.33 & 3.99 \\
\hline VVRCHC131 & VIT_18s0001g03270.t01 & Chr18 & 3233803 3234804 & 333 & 38.18 & 7.13 \\
\hline VVRCHC132 & VIT_18s0001g06640.t01 & Chr18 & $5000284 \sim 5003505$ & 405 & 44.98 & 5.15 \\
\hline
\end{tabular}


Table 1 Detailed information of all 143 VvRCHCs identified in grapevine genome (Continued)

\begin{tabular}{|c|c|c|c|c|c|c|}
\hline Gene name & Sequence ID & Chromosome & Localization & Protein Length $(a a)^{\mathrm{a}}$ & Molecular Weight $(\mathrm{kDa})^{\mathrm{b}}$ & $p l^{c}$ \\
\hline VVRCHC133 & VIT_18s0001g06670.t01 & Chr18 & $5020431 \sim 5021751$ & 398 & 44.25 & 9.09 \\
\hline VVRCHC134 & VIT_18s0001g10260.t01 & Chr18 & $8598100 \sim 8604904$ & 734 & 78.55 & 5.98 \\
\hline VVRCHC135 & VIT_18s0001g14530.t01 & Chr18 & $12533609 \sim 12536412$ & 334 & 37.20 & 4.34 \\
\hline VVRCHC136 & VIT_18s0075g00220.t01 & Chr18 & $21471547 \sim 21496753$ & 444 & 47.91 & 8.92 \\
\hline VVRCHC137 & VIT_18s0089g00860.t01 & Chr18 & $28686085 \sim 28689586$ & 221 & 24.97 & 5.05 \\
\hline VVRCHC138 & VIT_19s0014g01850.t01 & Chr19 & $2035536 \sim 2041782$ & 538 & 58.57 & 6.3 \\
\hline VVRCHC139 & VIT_19s0090g00400.t01 & Chr19 & $6551526 \sim 6553119$ & 220 & 24.03 & 6.51 \\
\hline VVRCHC140 & VIT_19s0015g01000.t01 & Chr19 & $9081946 \sim 9084990$ & 343 & 39.31 & 8.81 \\
\hline VVRCHC141 & VIT_00s0125g00250.t01 & Un & 1842078 1866688 & 497 & 56.09 & 5.07 \\
\hline VVRCHC142 & VIT_00s0264g00020.t01 & Un & 18991085 18993638 & 235 & 25.36 & 5.02 \\
\hline VVRCHC143 & VIT_00s0349g00040.t01 & Un & 24940977 24941538 & 135 & 15.22 & 8.12 \\
\hline
\end{tabular}

a a amino acid

${ }^{\mathrm{b}} k \mathrm{a} a$ kilo Dalton

${ }^{c} p /$ isoelectric point

while the $R C H C$ gene of Arabidopsis thaliana or tomato is found in each group. It is worth noting that more RCHC genes of Arabidopsis thaliana and tomato are gathered in group VI. Most of the RING-type C3H2C3 genes of grapevine display some homology to $\mathrm{RCHC}$ genes of Arabidopsis or tomato. In addition, some gene pairs showed high similarity in different groups, which were confirmed in the distance of evolutionary relationship, the location of RING conserved domain and the length of protein sequence. For instance, SlATL33 and
VvRCHC62, SlATL46 and VvRCHC108, SlATL51 and VvRCHC110, AtBRH1 and VvRCHC116, AtRHA1A and $V v R C H C 13, A t S D I R 1$ and VvRCHC97, AtRHC1A and $V v R C H C 59$ etc. Next, a phylogenetic tree containing only $143 \mathrm{VvRCHC}$ protein sequences was constructed. To facilitate their study and analysis, the 143 members were divided into 6 groups $(\mathrm{I} \sim \mathrm{VI})$ according to the classification and phylogenetic analysis of Fig. 3a, from which 27 pairs of genes with high homology were found. Based on their color-coded names, the VvRCHCs were

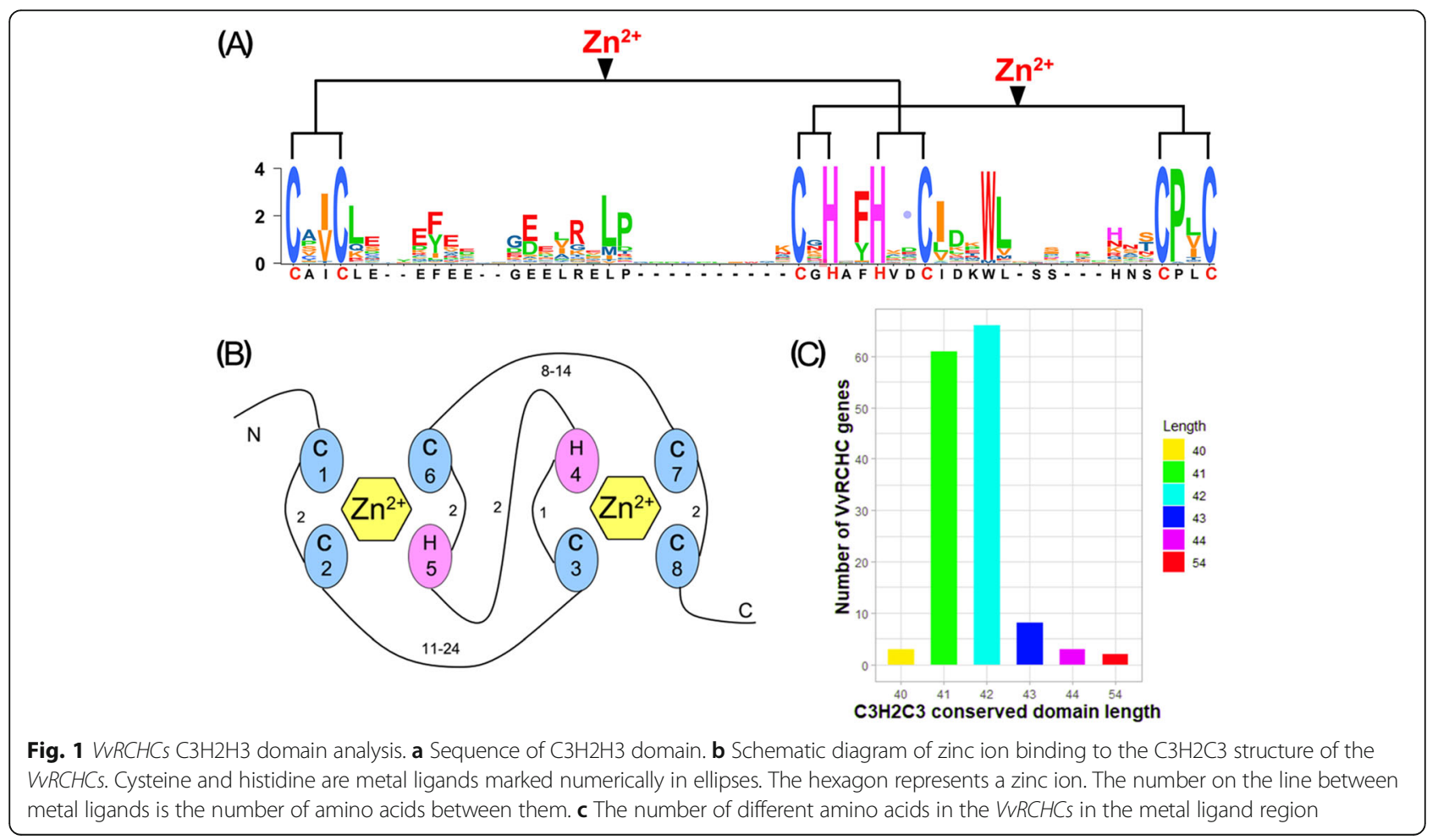




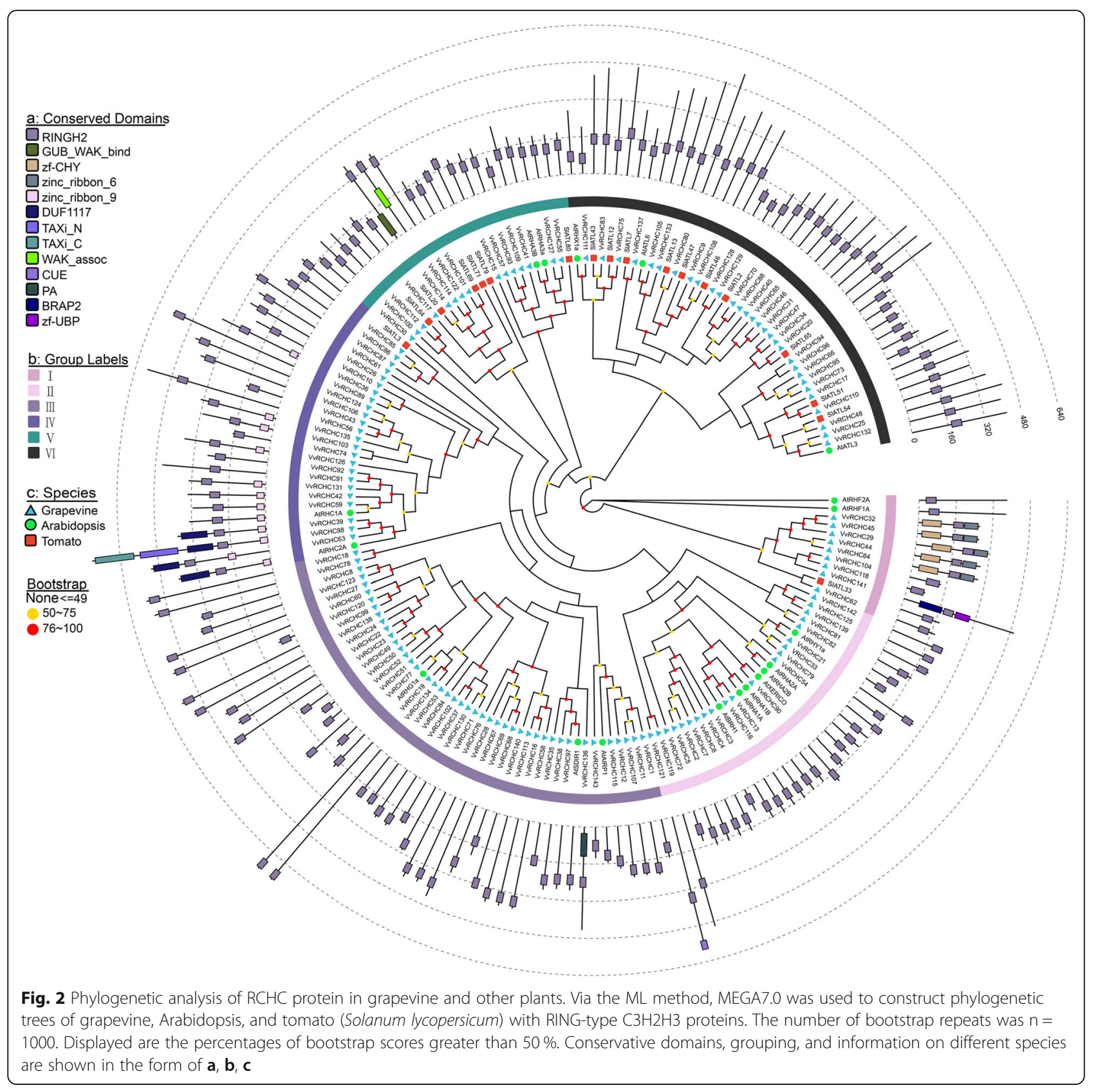

then divided into six groups according to the number of conserved amino acids in their protein sequence.

\section{Characterization of the motifs and gene structure of $V_{v R C H C s}$}

To further understand the diversity in motif composition between $V v R C H C s$, the MEME analysis of VvRCHC proteins from groups I to VI was carried out. From this, 12 conserved motifs were identified in the $\mathrm{VvRCHC}$ protein, named motif 1 to motif 12 (Fig. 3b), in which motif 1 and motif 2 is found in almost every $V v R C H C s$, this motif combines to form the eight most important metal ligand (Cys-Cys-Cys-His-HisCys-Cys-Cys) structures of every $V v R C H C$ gene.
Importantly, there are 13 such structures in some genes, such as PA, CUE, DUF1117, zinc_ribbon_9, and zf-CHY, among others. These structures domain could be relevant for the function of $V v R C H C s$. The sequence information of motif $1 \sim 12$ is presented in Table 2; Fig. 3d (motif data). We next analyzed the exons, introns, and several key structures of $V v R C H C s$ (Fig. 3c). Most VvRCHCs (67.13\%) had no more than 2 introns, with a maximum of 19 introns in $V v R C H C 29$ and none intron in $57 V v R C H C s$ (Fig. S3). The longest intron length was found in $V v R C H C 141$.

According to the phylogenetic analysis of $\mathrm{VvRCHCs}$ (Fig. 3a), 45 pairs of genes can be found in the 


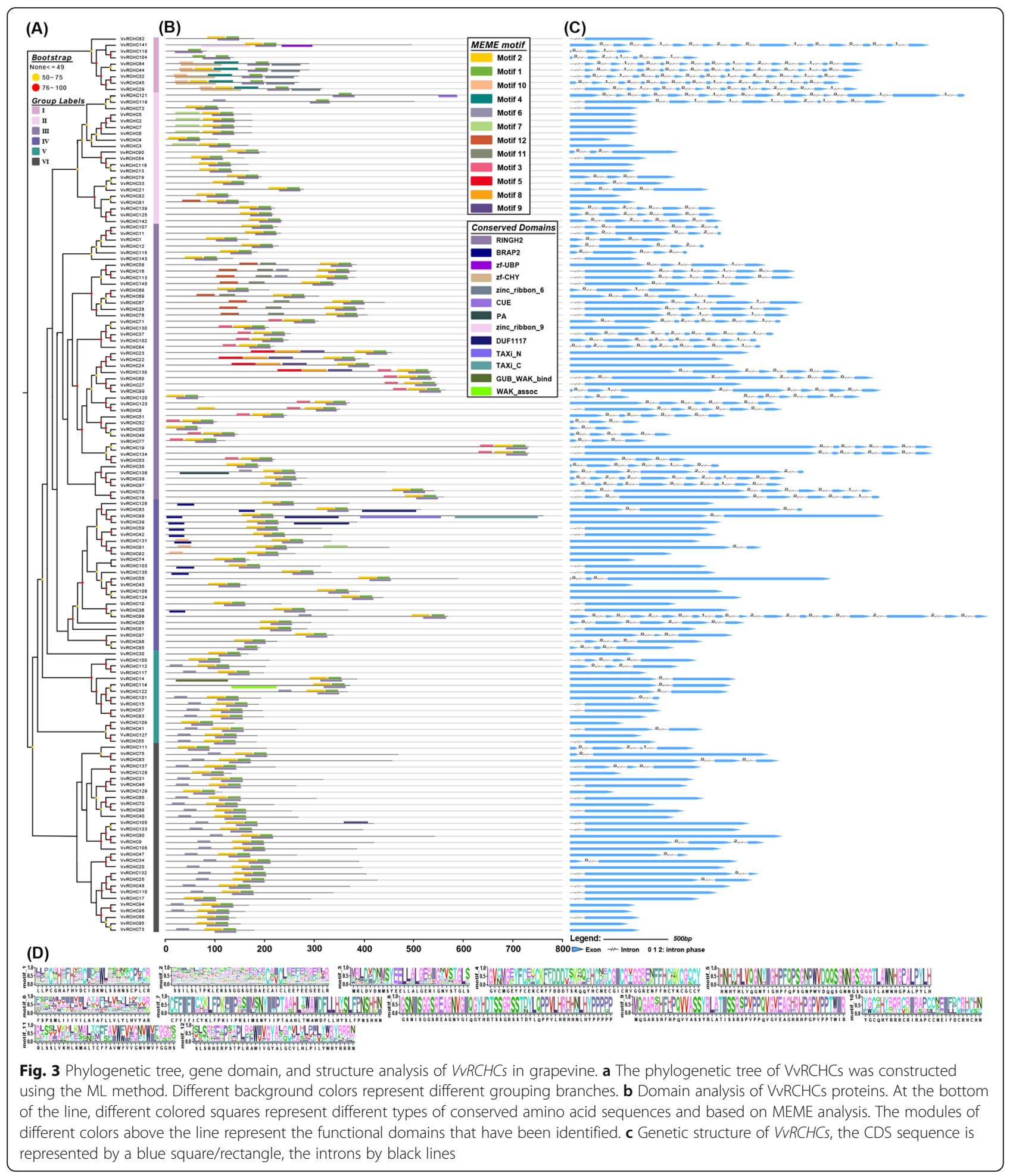

evolutionary tree. The results of the MEME and gene structure analyses of these gene pairs were also similar (Fig. 3b and c). For example, the conserved motifs in the protein sequences of $V v R C H C 44 / 64$ are highly similar, and the structure type and length are also similar, such as for $V v R C H C 94 / 96, V v R C H C 38 / 97, V v R C H C 18 / 78$, $V v R C H C 28 / 67$ and $V v R C H C 11 / 107$, to name a few. Unexpectedly, the MEME analysis of $V v R C H C 55 / 127$, $V v R C H C 105 / 133$, and $V v R C H C 13 / 116$ gene pairs gave near identical results to those from the gene structure 

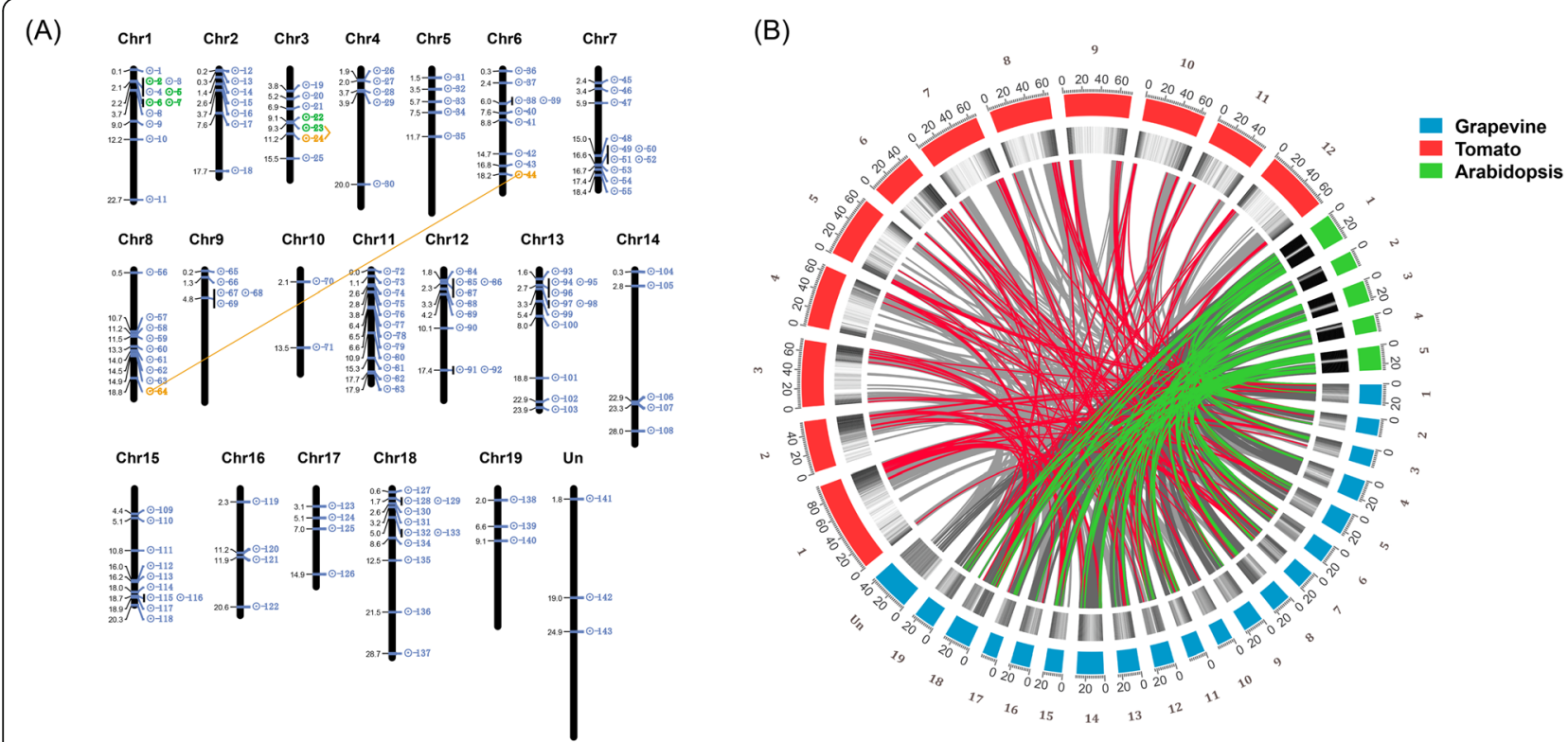

Fig. 4 Chromosome location, gene replication, and collinear correlation. a Location information of VVRCHCs on grapevine chromosomes. Colored boxes and line connections represent the segmental repetitive gene pairs. b Collinear correlations of RCHCS in grapevine, tomato, and Arabidopsis. Each colored square is a chromosome (serial number). The black-and-white square shows the density of genes in each chromosome. Each line connects homologous genes; colored lines correspond to RCHCs, while gray lines denote other genes

analysis, revealing a remarkably similar protein sequence length, gene structure length and the intron number among them. We thus speculate these four gene pairs may perform similar functions in grapevine plants.

\section{Chromosomal localization and gene replication analysis of $\mathrm{V} v \mathrm{RCHCs}$}

According to the location of $V v R C H C s$ in the grapevine genome, $143 \mathrm{VvRCHCs}$ were placed on 20 chromosomes (Fig. 4a), albeit unevenly distributed among them. Imprinting of the $V v R C H C s$ was found in each chromosome of grapevine, but the number of genes on different chromosomes varied. The most found were 12
VvRCHCs on chromosome 11, the $11 \mathrm{VvRCHCs}$ were identified on chromosome 1,7,13 and 18. Further, we also observed that these most of these $V v R C H C s$ are likely distributed at both ends of the chromosome, leaving only a small portion of them in its middle part. Gene replication events include tandem replication and segmental replication, which are very vital for expanding the number of members of the gene family. To clarify the amplification mechanism of $V v R C H C s$ during their evolution, we studied their potential repetitive events of VvRCHCs. According to the intraspecific alignment of $143 \mathrm{VvRCHCs}, 9$ pairs of genes, 7 and 2, were respectively identified as associated with tandem or segmental

Table 2 Motif data information in MEME analysis of VVRCHCS

\begin{tabular}{lll}
\hline Motifs & Protein sequences & Width \\
\hline Motif1 & LLPCGHAFHVDCIDKWLSSHNSCPLCR & width=27 \\
Motif2 & SSILSLTPKLEKSSGGSGEDAECAICLEEFEEGEELR & width=37 \\
Motif3 & MRLDVDNMSYEELLALGERIGNVSTGLS & width=28 \\
Motif4 & GVCMGEYFCEKCKFFDDTSKQQYHCDECGICRVGGRENFFHCKKCGCCY & width=50 \\
Motif5 & HNHYHLVQGNYIGHPFQPSGNPWVDQQSGNNGSGGGTLAWNHGPALPYLH & width=50 \\
Motif6 & FSPIMLIIJVILATAFLLVLLLHVYAR & width=27 \\
Motif7 & CFFIFICHKLFPKIIPRSIMSNYIIPTAAHLTWAWDFLLHYSLFPNSHHN & width=50 \\
Motif8 & GSNISGGSREAGNVGIQGYHDTSSGRSSTDYLQPPVLHRHHNLHYPPPPP & width=50 \\
Motif9 & MQGARRHFHPQWASSYRLATISSRSPVPPQVGVEAGHRHPGPVPPTWIR & width=50 \\
Motif10 & WGCQHYRRRCRIRAPCCNEIFDCRHCHN & width=28 \\
Motif11 & wLSSLVKHLKMALDCFFAWWFVIGNVWIFGGGS & width=38 \\
Motif12 & SLSRHERPSAPLFAWIVGYALGCVLTLPILYWRYRRRN & \\
\hline
\end{tabular}


Table $3 \mathrm{Ka} / \mathrm{Ks}$ analysis and divergence time estimated for grapvine duplicated VvRCHCs paralogs

\begin{tabular}{llllll}
\hline \multicolumn{2}{l}{ Paralogous Pairs } & Ka & Ks & Ka/Ks & Duplicate Type \\
\hline$V_{V R C H C 5}$ & $V_{V R C H C 7}$ & 0.143 & 0.674 & 0.212 & tandem \\
$V_{V R C H C 6}$ & $V_{V R C H C 5}$ & 0.146 & 0.341 & 0.429 & tandem \\
$V_{V R C H C 6}$ & $V_{V} R C H C 2$ & 0.093 & 0.191 & 0.486 & tandem \\
$V_{V} R C H C 7$ & $V_{V} R C H C 6$ & 0.080 & 0.277 & 0.290 & tandem \\
$V_{V} R C H C 7$ & $V_{V} R C H C 2$ & 0.106 & 0.285 & 0.372 & tandem \\
$V_{V R C H C 5}$ & $V_{V} R C H C 2$ & 0.226 & 1.102 & 0.205 & tandem \\
$V_{V} R C H C 23$ & $V_{V} R C H C 22$ & 0.017 & 0.040 & 0.431 & tandem \\
$V_{V} R C H C 24$ & $V_{V} R C H C 23$ & 0.019 & 0.020 & 0.951 & segmental \\
$V_{V R C H C 64}$ & $V_{V} R C H C 44$ & 0.166 & 0.929 & 0.178 & segmental \\
\hline
\end{tabular}

replication events. Among the 9 pairs of gene events, the tandem repeat frequency between chromosomes 1 was the highest, there were six tandem replication events, moreover, one pair of genes on chromosomes 3 identified as tandem replication genes. These results suggested that the main replication event mode of grapevine $V v R C H C s$ family is via tandem replication; hence, it could have played a crucial role in the amplification of $V v R C H C s$ during their evolutionary history.

To explore the selection of grapevine $V v R C H C s$ in terms of their repetition and differentiation, the nonsynonymous $(\mathrm{Ka})$, synonymous $(\mathrm{Ks})$, and $\mathrm{Ka} / \mathrm{Ks}$ of each duplicated $V v R C H C s$ were calculated. Among the 9 pairs of repetitive genes in grapevine, the $\mathrm{Ka} / \mathrm{Ks}$ values of one pair were less than 0.5 , while the average $\mathrm{Ka} / \mathrm{Ks}$ value was 0.325 . It is worth noting that 8 pairs had $\mathrm{Ka} / \mathrm{Ks}$ values less than 0.5 , indicating that most of the repeated grapevine $V v R C H C s$ were under negative selection during evolution (Table 3). Figure $4 \mathrm{~b}$ shows that grapevine, Arabidopsis, and tomato all retained similar $\mathrm{RCHC}$ genes in their evolutionary history. It is worth noting the absence of homologous genes with $V v R C H C 29$ in tomato, but their presence in Arabidopsis, which may have arisen from gene deletions in the process of evolution, given that the same genes are $V v R C H C 11$, $V v R C H C 38, V v R C H C 107, V v R C H C 119$, and $V v R C H C 137$. Nonetheless, two or more $R C H C$ genes in Arabidopsis and tomato were found homologous to one $V v R C H C$ gene; for example, $\quad V v R C H C 89$ and Solyc07g053850.3/ Solyc12g005470.2 and AT4G28370/AT2G20650, as well as those of $V v R C H C 1, V v R C H C 32, V v R C H C 97, V v R C H C 104$, $V v R C H C 118$, and $V v R C H C 142$. Hence, these genes may be parallel gene pairs and the putative source of amplifications of $R C H C$ genes during evolution.

\section{Cis-acting element analysis in $\mathrm{V} v R C H C s$ promoter}

To further investigate the transcriptional regulation of $V v R C H C s$, cis-acting elements in the 2000 bp region upstream of the $V v R C H C s^{\prime}$ codon was predicted. The predicted cis-acting elements can be divided into seven categories according to their functions: namely, light response (32), hormone response (11), growth and development response (9), stress response (6), enhanced promoter cis-acting (6), binding site cis-acting (6), and other functional cis-acting (2) elements. Most promoters of grapevine $V v R C H C s$ contained the CAAT-box or TATA-box, which are involved in the enhanced promoter cis-acting elements. In addition, 127 $V v R C H C s$ promoters harbored the stress response element ARE, more than half of the promoters of the $V v R C H C s$ having the hormone response elements ABRE, TGACG-motif, CGTCA-motif, and over half of the VvRCHCs also featured the G-box, GT1-motif, and Box 4 in their promoters (Table $\mathrm{S} 3)$. In the $2000 \mathrm{~kb}$ region upstream of $\mathrm{VvRCHCs}$, discovered many different functions of cis element, in addition to the common cis element with light response and enhanced the promoter, also found that the more growth and adversity stress related cis element, this suggests that $V v R C H C s$ may be widely participating in various life activities of plant.

It is known that the RING gene play a key role in plant growth and response to abiotic stresses. Accordingly, the cis-acting elements related to abiotic stress, growth and hormone regulation were focused upon here. The respective locations of the five major acting elements associated with hormone response, binding sites, growth and development, and stress of our concern, on the promoter of the $V v R C H C s$ (Fig. S4a) were determined. To accurately identify the stress-related elements, we focused on four kinds (anaerobic induction, injury response, low temperature, drought response (Fig. S4b), low temperature response, defense and stress response), whose locations are also depicted. In addition, we counted the number of major elements related to stress, growth and development, and hormone responses in the $V v R C H C$ gene promoter (Fig. S4b). Evidently, concerning growth and development, the number of $\mathrm{O}_{2}$-sites is the largest, there are 5 promoters of $V v R C H C 6$ and 4 promoters of $V v R C H C 40$. In terms of stress, the number of ARE is very large, found in $89 \%$ of the $V v R C H C s$ promoters, moreover, 5 of the most promoters of $V v R C H C 14$ and $V v R C H C 81$ occurred. In terms of hormone response, the number of ABRE is dominant, found in $64 \%$ of the $V v R C H C s$ promoters, moreover, 9 of the most promoters of $V v R C H C 3$ and $V v R C H C 16$ occurred. Surprisingly, 22 of the $V v R C H C 74$ gene promoters were found and 11 of the $V v R C H C 128$ gene promoters were found. These results suggest that $V v R C H C s$ may be associated with cis-acting elements of different functions; in other words, these genes may be regulated by these elements and thereby influence related plant life activities.

Expression analysis of $V v R C H C s$ in roots of two grapevine rootstocks with different drought sensitivity

To investigate differential $V v R C H C s$ ' expression between plants having contrasting drought-resistant genes 


\section{(A)}

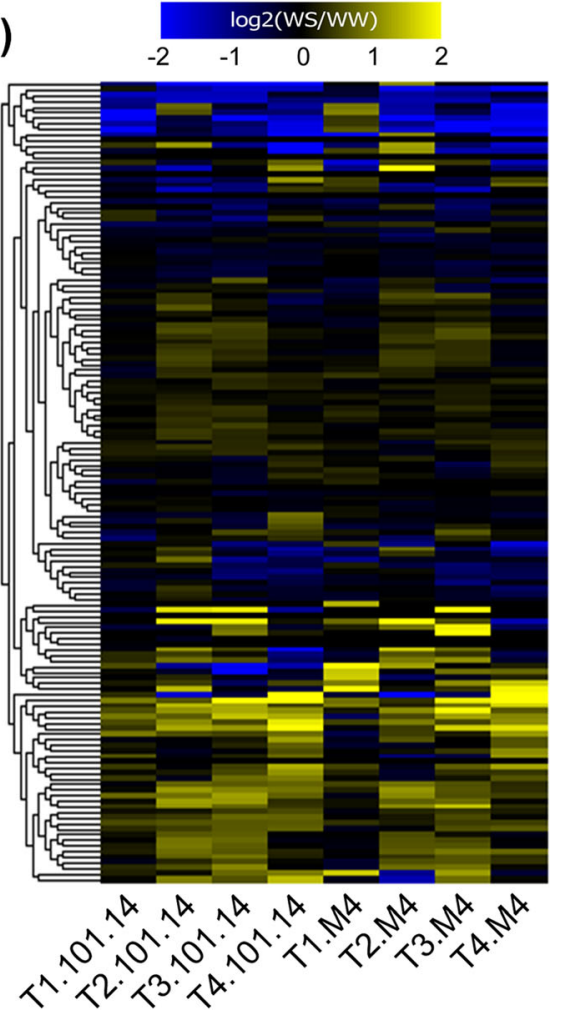

(B)

(C)

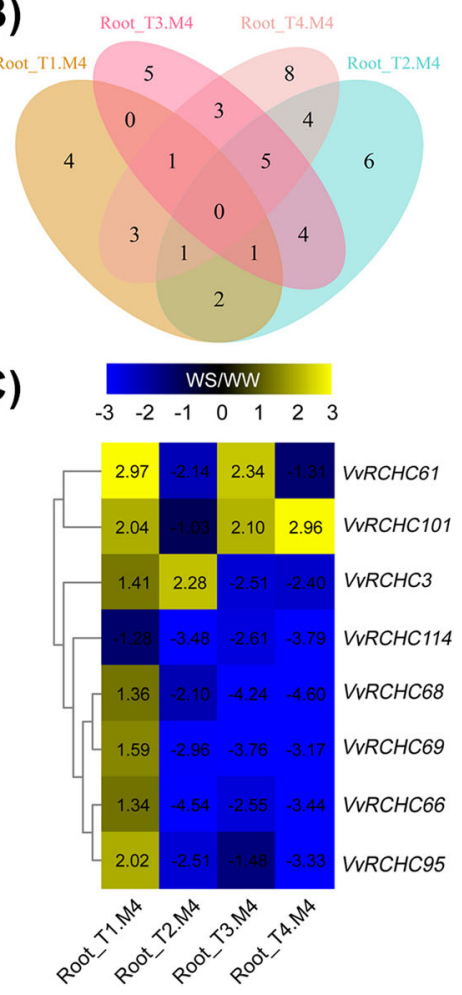

Fig. 5 Differential heat map of VVRCHCS expression in plants under drought stress conditions. a Heat maps of two different genotypes, based on their log2(WS/WW) values from the RNA-Seq data set, under drought stress and normal conditions at times T1-T4. $\mathbf{b}$ The Venn diagram of DEGs obtained from the analysis of the expression of M4 genotype at different periods. c Selected eight candidate genes in genotype M4 at different stages of WS/WW heat map

(101.14 vs. M4) under drought stress and their potential functioning, the grapevine RNA-Seq transcriptome database of the published dataset was used [24]. We checked

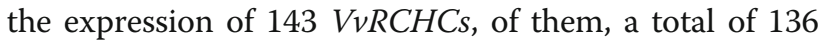
$V v R C H C s$ expression.To understand the expression of these $V v R C H C s$ under the drought treatment, we used the ratio of WS (Water Stress) to WW (Well-Watered) gene expression of the two genotypes to draw an expression heat map, expression values are reported as $\log _{2}(\mathrm{WS} / \mathrm{WW})$ fold change (Fig. 5a), the differential multiple matrixes of these $V v R C H C s$ is recorded in Table S4. However, more than $60 \%$ of the $V v R C H C s$ in the two genotypes were highly expressed under the imposed drought. To screen out the key genes, in each time period of the treatment, the gene that conforms to $\left|\log _{2}(\mathrm{WS} / \mathrm{WW})\right|>1$ is considered a differential gene, and the Venn diagram was made using the differentially screened genes of the drought-tolerant genotype M4 at different times (Fig. 5b). By looking at the different genes in each period, there are finally 8 genes that are different in three periods. To robustly verify the gene expression levels, the expression patterns of these 8 genes were verified by qRT-PCR (Fig. 6), whose pattern basically conformed to the trend shown in Fig. 5c. The
VyRCHC114 gene was significantly down-regulated at 2 days, with a strong downward trend of the drought treatment. The VyRCHC66, VyRCHC68, VyRCHC69 and $V y R C H C 95$ genes had a similar expression trend, being slightly up-regulated at 2 days of drought, but strongly down-regulated thereafter. These results suggested eight key genes are probably involved in regulating the plant response to drought.

\section{Identification of E3 ubiquitin ligase activity of VyRCHC114} To clarify whether VyRCHC114 has E3 ubiquitin ligase activity, we conducted an in vitro ubiquitin activity assay, achieved by using purified MBPVyRCHC114 fusion protein mixed with ubiquitin, E1, and E2 and by western blotting with the MBP antibody. Ubiquitin molecules were detected on the fusion protein linked by MBP antibody (Fig. 7a). This same method was used to detect ubiquitin antibody tags. The VyRCHC114 protein was detected in the fusion protein linked by the ubiquitin antibody, which indicated it had E3 ligase activity.

We know that the RING-C3H2C3 type protein can form a RING structure for ubiquitin regulation, but this process depends on the interaction between 


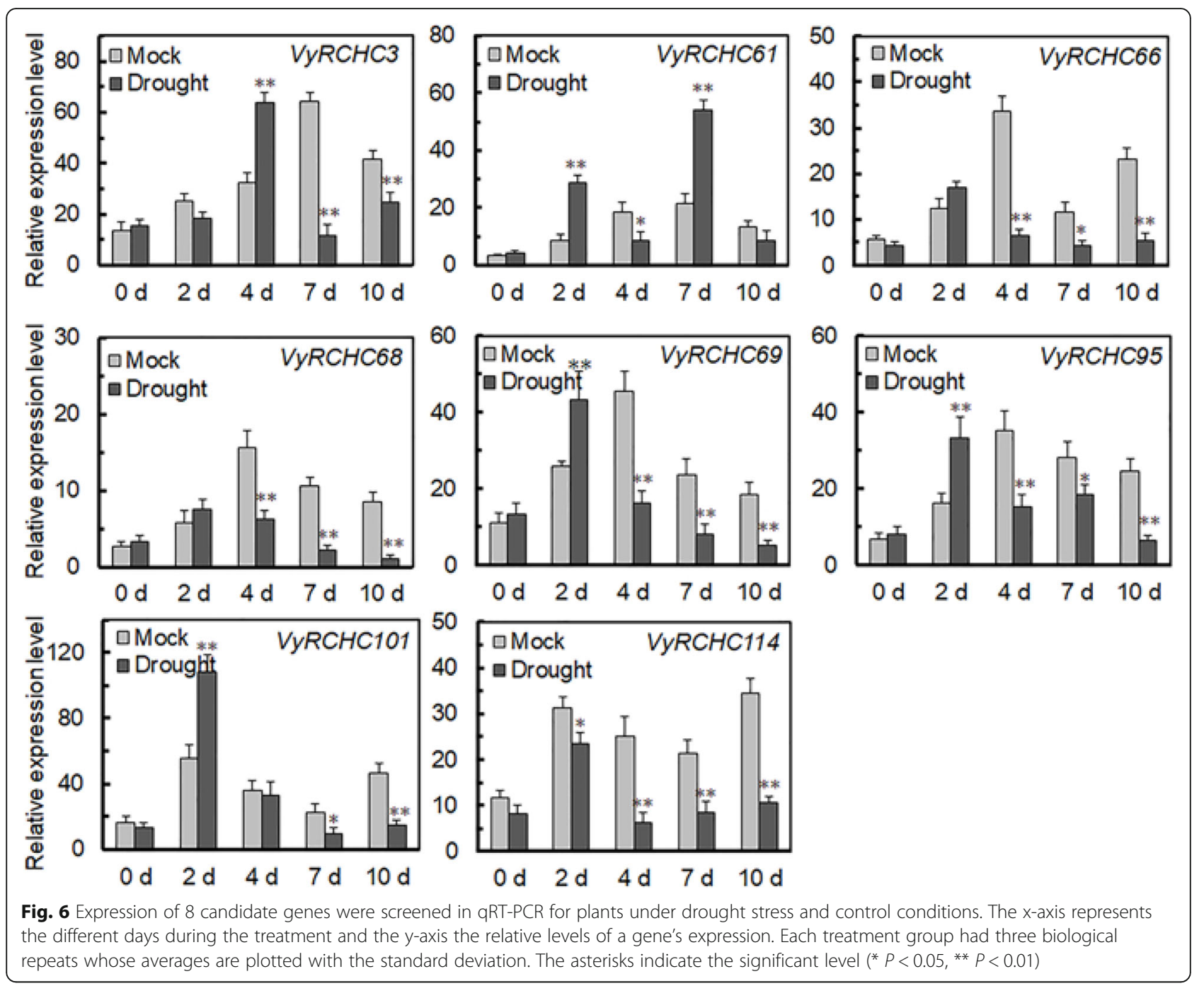

the eight conserved metal ligands. To further illustrate whether and how E3 ligase activity of VyRCHC114 depends on these conserved metal ligands, as shown in Fig. 7c, we selected four different amino acid sites for mutation (two key conservative and two non-conservative metal ligand sites). Four corresponding proteins (C320S, C328S, H341A, N355A) were obtained, and their ubiquitin activity in vitro was tested by the same method. After the immuno-blotting analysis of MBP antibody and ubiquitin antibody, evidently the two mutant proteins C320S and H341A lost their E3 ubiquitin ligase activity due to mutations at key sites, but the two mutant proteins C328S and N355A maintained theirs (Fig. 7b). The unprocessed original image is in Fig. S6. These results indicated these conserved metal ligand sites are crucial factors for demonstrating the $\mathrm{VyRCHC} 114$ ligase activity.

\section{Overexpression of $\mathrm{VyRCHC114}$ enhances Arabidopsis} drought tolerance

To clarify the effects of $V y R C H C 114$ 's role in plant responses to drought, we selected transgenic Arabidopsis (OE \#2, \#5, \#13) with high expression levels of the $V y R C H C 114$ gene for subsequent experiments (Fig. 8b). After 15 days of drought imposed upon wild plants and transgenic plants, followed by normal watering for 6 days, phenotype observations revealed that plants overexpressing $V y R C H C 114$ had significantly improved the drought tolerance (Fig. 8a). Further, on average, more than $70 \%$ of the plants overexpressing VyRCHC114 survived the drought stress, which was significantly higher than the $30 \%$ survival rate of the EV-transformed group (Fig. 8c).

To understand the relationship between plant growth and drought resistance, electrolyte leakage rates (Fig. 9a) and chlorophyll content (Fig. 9b) were both measured. These were similar between $V y R C H C 114$-overexpressed 


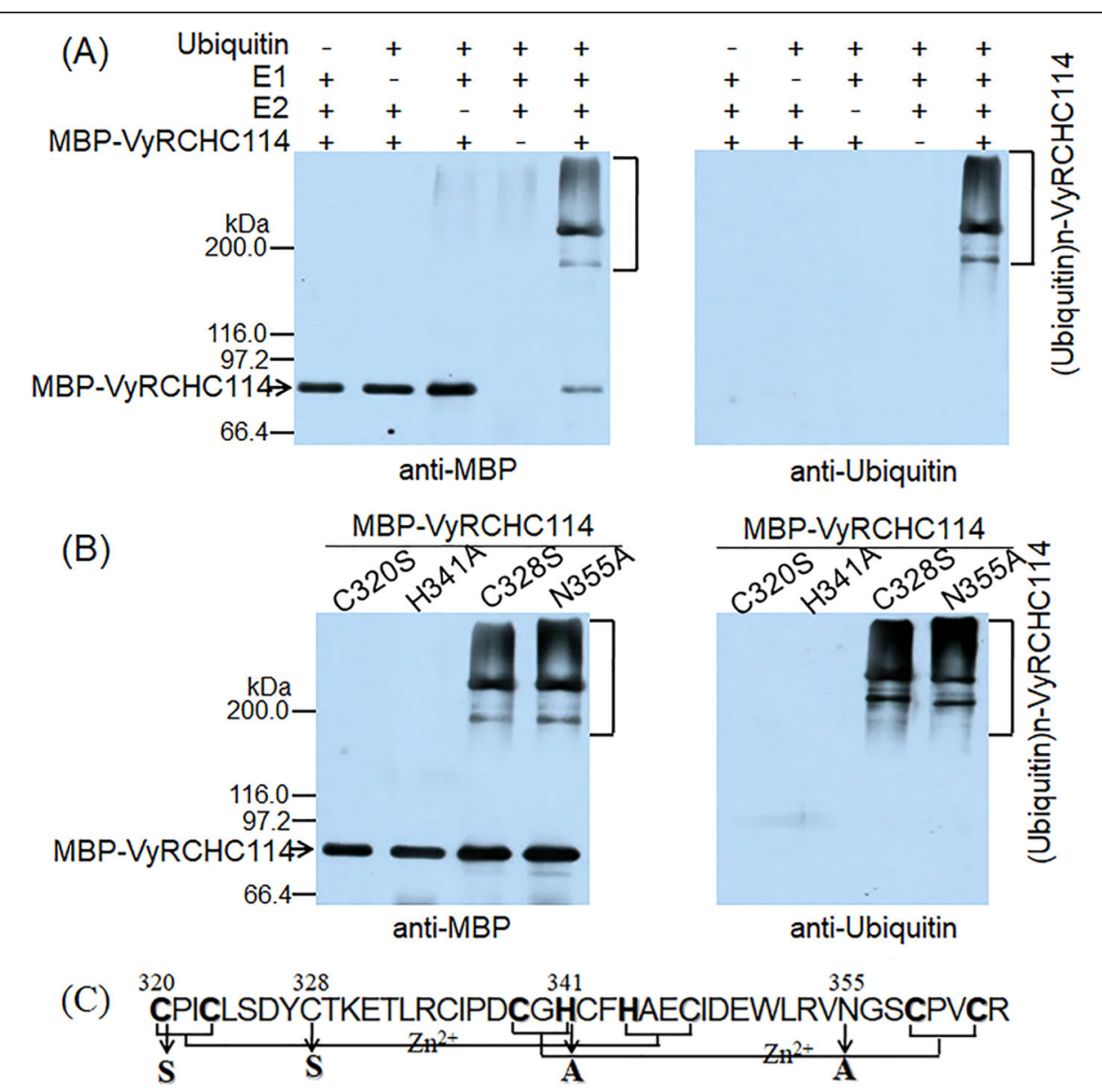

Fig. 7 E3 ubiquitin ligase activity of VyRCHC114. a Determination of E3 ubiquitin ligase activity of VyRCHC114; an immunoblot analysis was performed with the ubiquitin antibody (right) and MBP antibody (left). b Determination of E3 ubiquitin ligase activity of VyRCHC114 mutants; an immunoblot analysis was performed with ubiquitin antibody (right) and MBP antibody (left). c Schematic diagram of VyRCHC114 C3H2C3 domain and putative mutation sites. C328S and N355A affect a non-conserved site of the VyRCHC114 C3H2C3 domain. Mutations in C320S and H341A affect the ubiquitin activity of VyRCHC114

and EV-transformed plants in the non-stress treatment, but after 8 days of drought stress, the electrolyte permeability of the former was significantly lower than the latter, while the chlorophyll content was significantly higher in overexpressing than EV-transformed plants. Additionally, the changes in photosynthesis under drought stress were further analyzed by measuring potential photosynthetic efficiency (Fig. 9c) and capacity storage capacity (Fig. 9d). Each was not significantly different from EV-transformed and $V y R C H C 114$ overexpression plants under non-stress; however, $\mathrm{Fv} / \mathrm{Fm}$ was significantly higher in the latter than the former at 4 days, and especially at 7 days, of drought stress. At 4 days, energy storage capacity of $V y R C H C 114-$ overexpressed plants was not significantly different from that of EV-transformed plants, but at 7 days of drought stress, that of the former exceeded the latter. Hence, these results suggest that $V y R C H C 114$ can enhance the drought resistance of plants by participating in the regulation of photosynthesis.
Many studies have shown that antioxidant enzymes can influence plants' drought tolerance. Common antioxidant enzymes are ascorbate peroxidase (APX), superoxide dismutase (SOD), peroxidase (POD), and catalase (CAT), so we examined their activity. As Fig. 10 shows, under non-stress conditions, the activity of these antioxidant enzymes was similar between the plants, whereas when drought stressed for 4 and 7 days, the activities of APX (Fig. 10a), SOD (Fig. 10b), POD (Fig. 10c) and CAT (Fig. 10d) were significantly higher in plants overexpressing $V y R C H C 114$ than those EV-transformed. Taken together, these data indicate VyRCHC114 may also improve drought tolerance by elevating antioxidant enzyme activity.

AtCOR15a, AtERD15, AtP5CS1, and AtRD29A are known to be key genes for regulating plant responses to drought stress. So we quantified their expression of imposed drought. As expected, when non-stressed, there was no significant difference between plants 

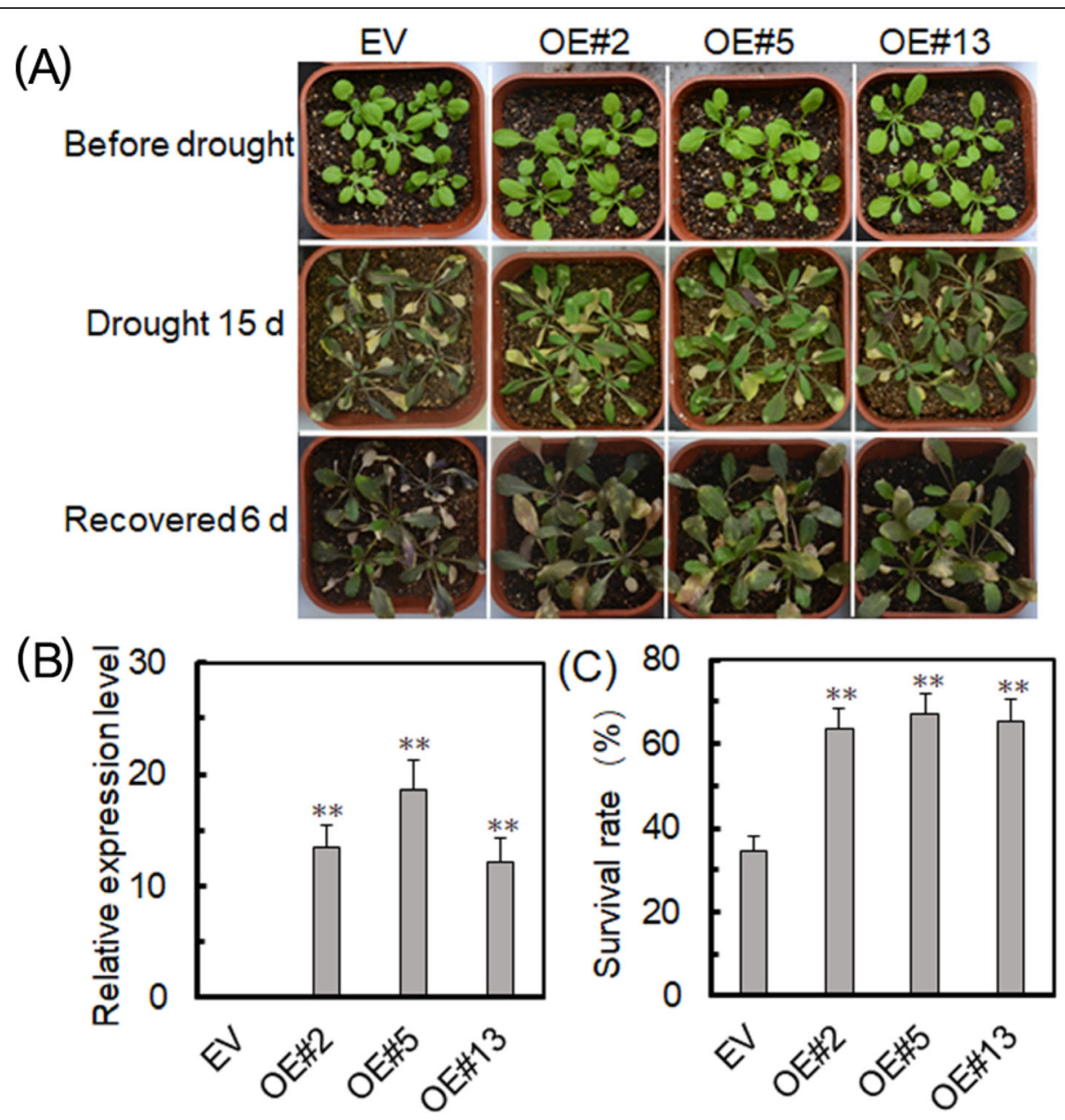

Fig. 8 VyRCHC114 overexpression (OE) enhances drought resistance in Arabidopsis. a Phenotypes of three transgenic and an EV-transformed Arabidopsis lines after 15 days of drought stress and a 6-day recovery period. b, c Relative expression levels of VyRCHC114 and survival of transgenic and EV-transformed Arabidopsis plants. Data are the mean \pm SD (standard deviation). The asterisk, $\left(^{*}\right)$ and $\left(^{* *}\right)$, indicate that OEs and EV-transformed groups were significantly different at $P<0.05$ and $P<0.01$ (Student's t-test)

overexpressing $V y R C H C 114$ overexpression and those EV-transformed. By contrast, under drought stress, all four genes were significantly higher in $V y R C H C 114-$ overexpressed plants than in those EV-transformed (Fig. 11).

\section{Discussion}

The RING C3H2C3 gene family has since been identified with many plant species [25-28]. Related studies have shown that RING genes are involved in a variety of biological processes, growth and development and hormonal responses, as well as plant responses to abiotic stresses [29]. However, for grapevine, the RING $\mathrm{C} 3 \mathrm{H} 2 \mathrm{C} 3$ gene had not yet been identified in its whole genome, with few reports available on its relevance for grapevine growth and developmental regulation or response to abiotic stress. In our study, we analyzed the whole genome of grapevine for the RING $\mathrm{C} 3 \mathrm{H} 2 \mathrm{C} 3$ gene family members. Using the criteria of whether the eight conserved metal ligands are present, a total of 143 nonredundant RING $\mathrm{C} 3 \mathrm{H} 2 \mathrm{C} 3$ genes were thus identified. Studies have shown that grapevine's genome size is about 0.5 times that of tomato, containing 0.75 times as many genes as tomato [30, 31]. According to the known RING C3H2C3genes in tomato, the genes account for 0.58 in grapevine, which lies between the multiples of genome length and the number of genes [26].

Many RING C3H2C3 of E3 ubiquitin ligases belong to the ATL gene family [32]. According to Arabidopsis and tomato RING C3H2C3 genes, we divided grapevine's RING C3H2C3 genes into six categories (I VI) (Fig. 2). Each group has Arabidopsis or tomato in the same branch. This shows that grapevine genes have sequence similarity with Arabidopsis thaliana and tomato genes. Gene replication can arise from fragment replication, tandem replication, transposable events, and even whole 

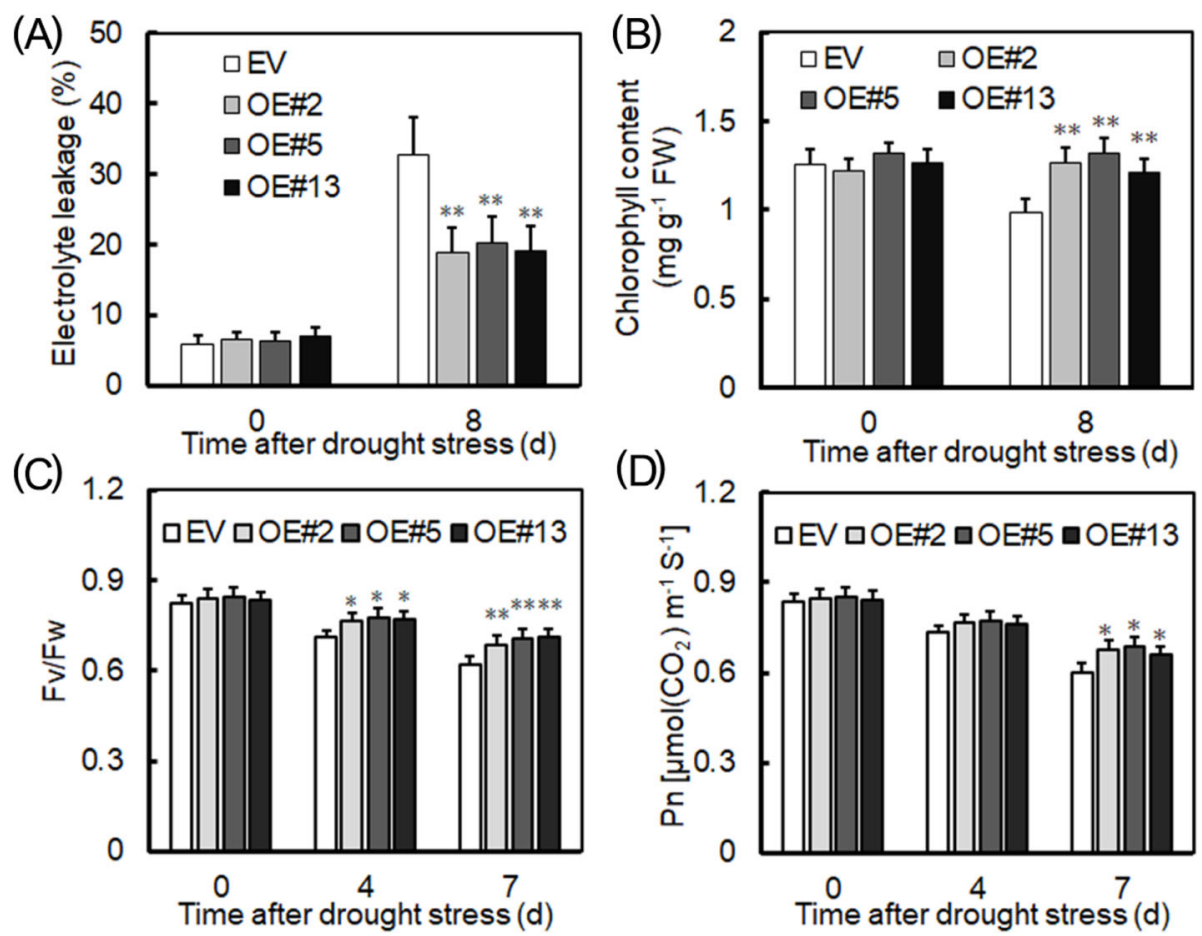

Fig. 9 Physiological indices of the EV-transformed and overexpressing (OE) Arabidopsis plants after drought stress. a Electrolyte leakage, $\mathbf{b}$ chlorophyll content, $\mathbf{c}$ PSII maximal photochemical efficiency (Fv/Fm), $\mathbf{d}$ net photosynthetic rate of leaves (Pn) were evaluated. Data are the mean \pm SD (standard deviation). The asterisk, $\left(^{*}\right)$ and $\left(^{* *}\right)$, indicates that OEs and EV-transformed groups were significant different at $P<0.05$ and $P<0.01$ (Student's t-test)
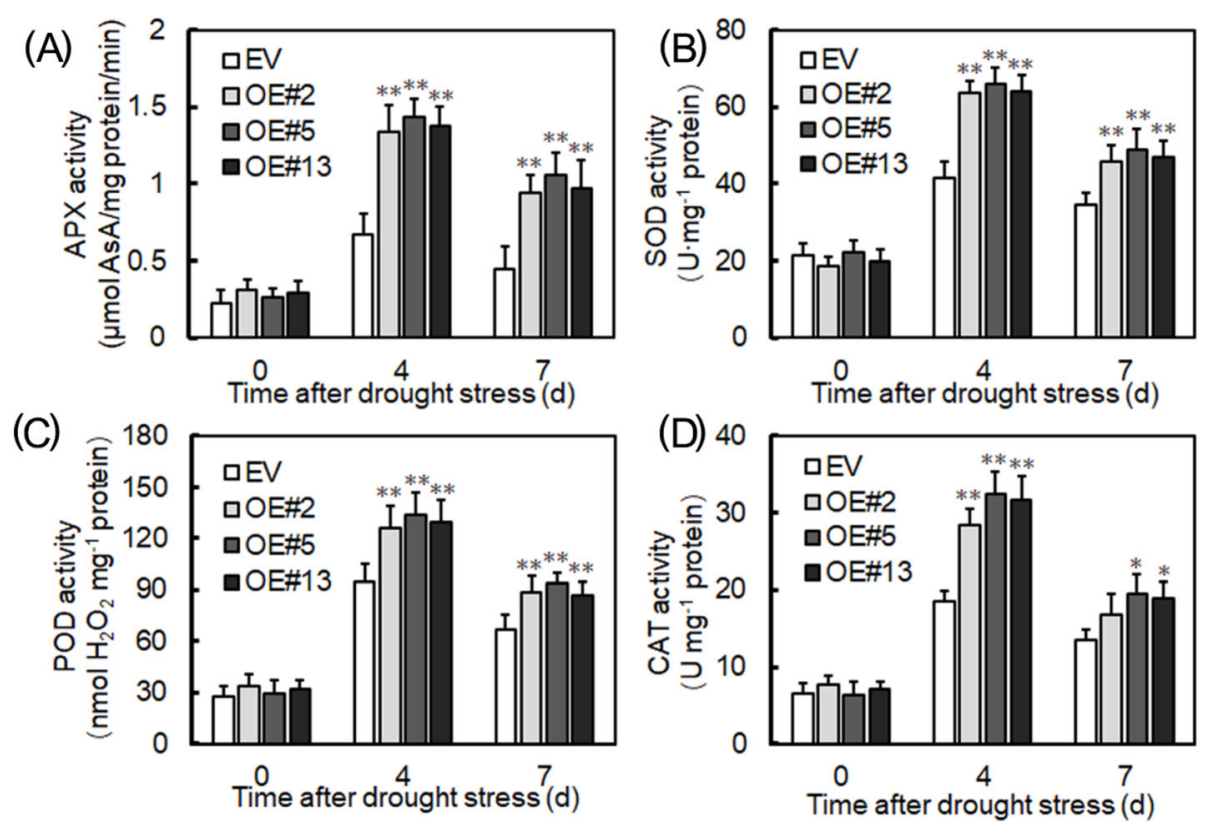

Fig. 10 VyRCHC114-overexpressed and EV-transformed plants' activity of various antioxidant enzymes in Arabidopsis. a Under drought stress for 0, 4, and 7 days, are ascorbate peroxidase (APX), $\mathbf{b}$ superoxide dismutase (SOD), c peroxidase (POD), $\mathbf{d}$ catalase (CAT) activities of overexpressed (OE) and EV-transformed plants were determined. Data are mean \pm SD (standard deviation). The asterisk, $\left(^{*}\right)$ and $\left(^{* *}\right)$, indicates that OEs and EVtransformed groups were significantly different at $P<0.05$ and $P<0.01$ (Student's t-test) 

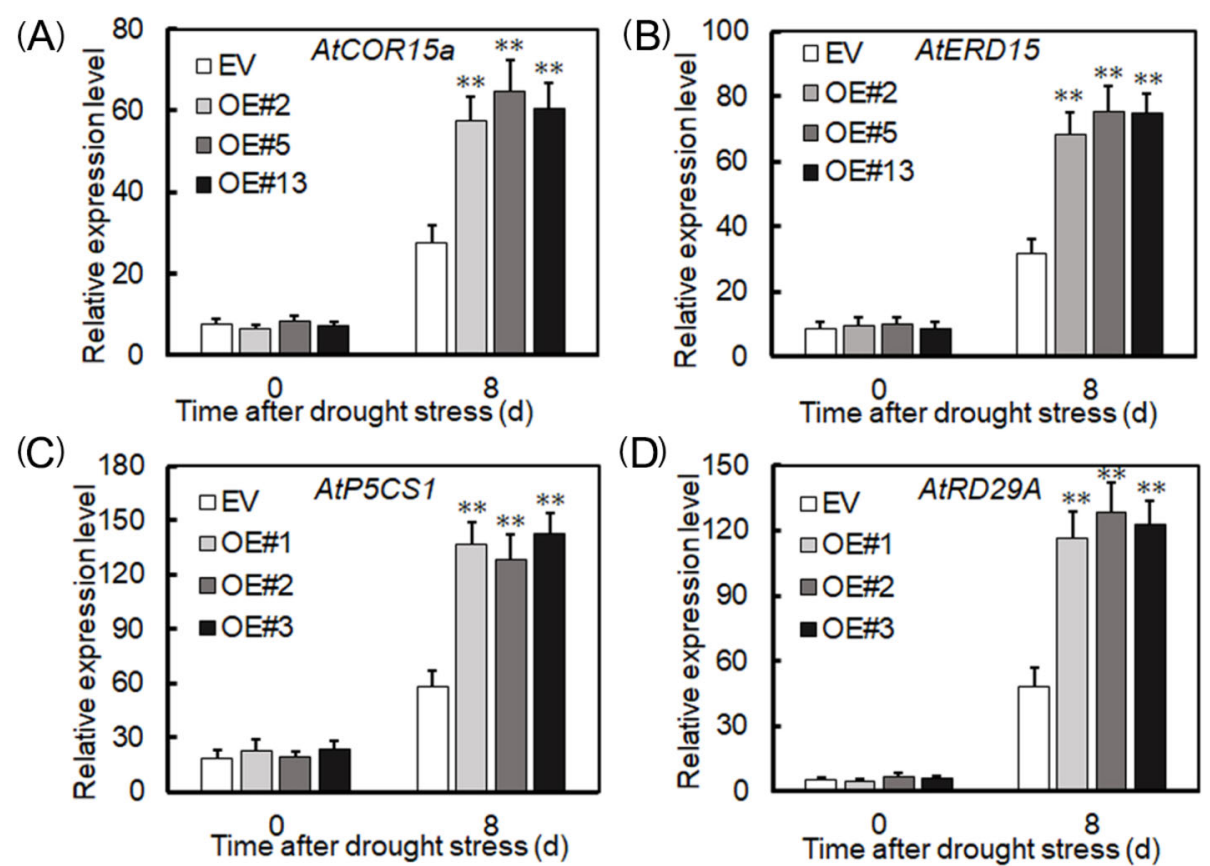

Fig. 11 Relative expression levels of drought resistance genes in transgenic and EV-transformed Arabidopsis after drought stress. a AtCOR15a, b AtERD15, c AtP5CS1, d AtRD29A. Data are the mean \pm SD (standard deviation). The asterisk, $\left(^{*}\right)$ and $\left({ }^{* *}\right)$, indicates that overexpressed (OEs) and EVtransformed groups of plants were significantly different at $P<0.05$ and $P<0.01$ (Student's t-test)

genome replication, which not only provide the evolutionary potential for species to produce new functional traits but also are a main driving force for species differentiation [33, 34]. In the identification of gene families from many species, gene replication events have proven instrumental in their expansion [35]. Studies have shown that tandem replication often occurs in widely and fast evolving gene families, a good example being Nucleotide Binding Sites Leucine Rich Repeat (NBS-LRR) resistance families [36]. Segmental replication is more common in slow evolving gene families, like the MYB gene family [36]. There are 7 pairs of genes in $V v R C H C s$ that are duplicated in tandem, and 2 pairs of genes are duplicated in segments. Tandem replication may be the cause of $V v R C H C s$ expansion, like the WRKY family genes in the autopolyploid Saccharum spontaneum [37]. The collinearity analysis of $V v R C H C s$ with Arabidopsis and tomato explains the homology relationship between grape $\mathrm{RCHC}$ gene and tomato is closer. In addition, $54 \mathrm{VvRCHCs}$ were found to be homologous to genes in Arabidopsis and tomato, these genes may be preserved by the ancestors of dicots.

Cis-acting elements in gene promoter regions may be critical for gene regulation. Plant hormone regulation, growth and development, and stress were common upstream of different $V y R C H C s$. This situation is in fact rather common in RING genes of all species [25-28]. The ubiquitin-proteasome system has been implicated in the control of the ABA response at different points of the
ABA pathway [38]. ABRE is ubiquitous in the promoter of $V v R C H C s$ (Fig. S4), Ubiquitin ligase SDIR1 regulates stress-responsive abscisic acid signal by interacting with ABRE abscisic acid response element [39]. There are ABRE elements in the promoters of $V v R C H C 3, V v R C H C 16$ and $V v R C H C 74$, which may be induced by the regulation of abscisic acid. ABA, GA, ethylene, trauma, drought, heat stress, and pathogen response elements are present in the promoter region of OsRING genes of rice plants, for which pathogen infection, SA, ABA, JA, and ethephon (ET) treatments could induce target genes expression to different degrees [40]. A similar analysis of RING gene ZmRHCP1 was recently done in maize [41]. Similarly, there are at least seven types of hormone regulatory binding elements in the promoters of $V v R C H C 39, V v R C H C 65, V v R C H C 126$ and $V v R C H C 129$, they may be responding to a variety of hormone regulation.

According to the analysis of RNG-Seq data set (Fig. 5a), more than $60 \%$ of $V y R C H C s$ were significantly upregulated or down-regulated under drought stress, indicating those genes may play a key role in how grapevine responds to drought. Studies have revealed the molecular mechanism of many circular genes involved in the drought stress. For example, in Arabidopsis, XERICO, SDIR1, AtAIRP1, AtAIRP2, AtAIRP3 and AtAIRP4 has been found to play a key role in the drought response of plants. In addition, E3 ubiquitin ligase atrzf1 mutation 
increased the proline content of Arabidopsis and improved drought tolerance [42]. GpDSR7 encodes an E3 ubiquitin ligase, which overexpressed in Arabidopsis increased its tolerance to drought stress [43]. In our study, focused on genes which were significantly up-regulated or down-regulated at four time periods during the drought treatment according to previous screening methods [44], as they more likely to play a key role in grapevine's drought stress response (Fig. $5 \mathrm{~b}$ and c). Comparing the RNA-Seq dataset with the RT-qPCR data (Fig. 6), it was found that the VyRCHC114continues to be downregulated. Hence, we postulated the $V y R C H C 114$ may possess E3 ubiquitin ligase activity and as a negative regulatory factor to respond to drought stress. Verifying this, we detected that $V y R C H C 114$ has E3 ubiquitin ligase activity (Fig. 7) and the $V y R C H C 114$ gene is overexpressed in Arabidopsis (Fig. 8). The results show the overexpression of $V y R C H C 114$ gave Arabidopsis drought resistance. This is not in line with expectations. Use the two reference models in Fig. S5 to explain the experimental results. Pattern 1: After VyRCHC114 degrades target protein $\mathrm{A}$, protein $\mathrm{B}$, which is functionally redundant with $\mathrm{A}$, is strongly activated, which gives plants stronger drought resistance. Genes with redundant functions often come from the same gene family, they generally have similar conserved domains and participate in various life activities together [45]. the five MIR172 have redundancy in the regulation of Arabidopsis meristem size, stem elongation and flowering [46]. AtUBP12 and AtUBP13 have functional redundancy in plant immunity, circadian clock, and photoperiod flowering regulation $[47,48]$. Pattern 2: After VyRCHC114 degrades target protein $\mathrm{A}$, protein $\mathrm{B}$, which competes with $\mathrm{A}$, is not inhibited, and continues to regulate downstream gene expression. This kind of competitive relationship is often accompanied by a complicated regulatory network. There are studies describing similar that ERF4 and MYB52 regulate downstream gene expression in an opposite manner by antagonizing each other's DNA-binding ability through a physical interaction [49]. Fig. S5 show interesting and complex networks. The results that are not in line with expectations have prompted more attention to the target protein of VyRCHC114. The preliminary pattern diagram (Fig. S5) gives us confidence. In addition, overexpression of VyRCHC114 caused changes in many related indexes, including antioxidant enzyme activity, photosynthesis rate, active oxygen metabolism and drought resistance gene expression. The results also indirectly prove that the targeted degradation substrate of the gene may be a key regulatory factor in the process of drought stress, and its degradation strongly activates other elements to resist drought stress, thus giving plants stronger drought resistance. It's going to be an interesting story. In the next work, we will identify the substrate protein of $\operatorname{VyRCHC114}$, further study its regulatory pathway, sequence the transcriptome of Vitis yeshanensis under drought stress, the co-expression networks under drought stress, and compare the differences of drought resistance of other cultivated species.

Drought stress greatly impacts the photosynthesis of plants, by affecting their photosynthetic rates and carbon metabolic pathways [50]. A lowered rate of photosynthesis can lead to excessive accumulation of reactive oxygen species (ROS), leading to cytotoxicity, membrane lipid peroxidation, and even cell death which can be countered by antioxidant enzymes as a form of plant defense [51, 52]. The overexpression of maize E3 ubiquitin ligase gene in transgenic tobacco can reportedly improve the drought resistance of tobacco [53]. Not only that, other abiotic stresses may also be regulated by photosynthesis, thus enabling plants to adapt to stress conditions [54]. According to our results, VyRCHC114 overexpressing plants maintained a strong photosynthetic rate and energy storage capacity while under drought stress. The reason for this may be an increase in their chloroplast content, pointing to $V y R C H C 114$ 's possible involvement in the regulation of chlorophyll biosynthesis pathway as an E3 ubiquitin ligase. Nonetheless, we also examined the expression of genes known to play a major role in drought stress responses to plants [5557]. Our results revealed that the expression levels of these genes were significantly higher in $V y R C H C 114$ overexpressed than EV-transformed Arabidopsis plants. Moreover, antioxidant system may be involved in plant abiotic stress tolerance mediated by the E3 ubiquitin ligase. Here, we provide physiological evidence that $V y R C H C 114$ heterologous expression enhances drought resistance by increasing the activity of antioxidant enzymes, which can scavenge for and eliminate ROS to indirectly reduce membrane damage.

\section{Conclusions}

$V y R C H C$ may act as an E3 ligase to mediate substrate degradation through the ubiquitin proteasome mechanism. This interaction may cause the target protein to be labeled by ubiquitin signaling, which leads to proteasome degradation. Since $V y R C H C 114$ likely represents a new class of positive /negative regulatory factors of the drought signal pathway, however, positive/negative depends on the regulatory characteristics of the target protein, but we think the degraded protein is a positive regulator of drought signaling, so that more of this substance may activate drought signaling. Therefore, VyRCHC114 may improve the water retention ability and antioxidant defense of plants by regulating their chlorophyll content and antioxidant system, thus participating in drought stress response. So far, however, the 
target protein of the plant $V y R C H C 114$ gene has not been determined, nor is the mechanism of augmented SOD, POD, APX and CAT activities clearly understood. In future work, we will focus on the identification of VyRCHC114 target proteins under drought stress and activation mechanisms of the antioxidant system in VyRCHC114-transgenic plants.

\section{Methods}

\section{Plant materials}

The grapevine variety Vitis yeshanensis was sampled from the field, located in the grape germplasm resource garden of Northwest A\&F University. Annual plants are selected for treatment, and the treatment method is the same [58]. Root samples were taken at 0d, 2d, 4d, 6d, 8d and $10 \mathrm{~d}$ respectively for subsequent experiments. Transgenic and wild type (WT) plants of Arabidopsis thaliana ecotype Columbia (Col-0) plants were grown in vermiculite: perlite $(1: 1, \mathrm{v} / \mathrm{v}) \mathrm{mix}$ in plastic pots in a growth chamber. Arabidopsis plants were grown in a soil mix of peat moss, perlite, and vermiculite $(3: 1: 1, \mathrm{v} / \mathrm{v} / \mathrm{v})$ under a $12-\mathrm{h} / 12$-h day/night cycle at $25^{\circ} \mathrm{C}$ with $60 \%$ relative humidity. For the drought stress treatment, plants were transformed with an empty vector (EV) or to overexpress $V y R C H C 114$ (OE\#2, OE\#5, or OE\#13 lines) [59], all of which were grown on individual MS medium plates for 7 days before transplantation into soil, there were 5 strains in the control and three transgenic lines. This experiment mainly followed previous research methods, albeit slightly modified [60]. After 3 weeks, these plants received a 12-day drought stress treatment (no water provided), after which they were re-watered and their survival recorded 6 days later. All experiments were repeated three times.

\section{Identification of RING-type $\mathrm{C} 3 \mathrm{H} 2 \mathrm{C} 3$ genes in the grapevine genome}

To identify the C3H2H3 type of RING, the most recent grapevine genome file in the Ensembl Plants Database (http://plants.ensembl.org/index.html) was downloaded and used. The grapevine RING C3H2C3 candidates were identified based on the HMM profiles (PF13639 and PF12678) with an e-value cutoff of 0.01. The screened proteins screened were given to Pfam (http://pfam.xfam. org/search/) and SMART ( ttp://smart.embl-heidelberg.de/), e value less than 0.01 . According to the results of PFAM, SMART database protein domain identification, extract $\mathrm{RCHC}$ conservative domain sequences in the VyRCHC protein sequence, and use CLUSTALX 2.0 to perform multi-sequence alignment, see if conserved Cys-Cys-Cys-His-His-Cys-Cys-Cys. Finally, 143 proteins that ultimately meet the conditions. The physicochemical properties of each RING-type C3H2C3 protein were predicted using the Protparam online tool (https://web. expasy.org/protparam/). The $143 \mathrm{~V} v \mathrm{RCHCs}$ were named according to their positional information on the chromosomes.

\section{Bioinformatics analysis of $\mathrm{VyRCHCs}$ family}

CLUSTALX 2.0 software was used to perform a multiple-sequence alignment of the 143 grapevine genes and the 18 tomato and 19 Arabidopsis $\mathrm{RCHC}$ protein sequences; it was also used to manually remove any untrusted gaps at both sequence ends. A phylogenetic tree was generated in MEGA 7.0 using the ML (maximum likelihood) method and bootstrapping with $\mathrm{n}=$ 1000 replicates, with all other settings set to their default values; the online EVOLVIEW (https://www.evolgenius. info/evolview/\#login/) tool carried out the tree's visualization. The online program Gene Structure Display Server 2.0 (http://gsds.cbi.pku.edu.cn/) was used to identify the genetic structure the $V v R C H C s$. Using the MEME online program (http://MEME.nbcr.net/meme/ introduction.html), the $\mathrm{VvRCHC}$ protein sequences could be analyzed under these parameters: an optimal motif width of $6 \sim 35$ and a maximum number of motifs of 12. According to the annotated positions in grapevine genome data, the 143 grapevine $V v R C H C s$ were located on 20 chromosomes. By referring to previous studies, BLASTN was used to compare the CDS sequences of $V v R C H C s$ in grapevine and tomato (e-value $=1 \times 10^{-10}$, homology $>75 \%)$. The tandem repeat gene pairs and segment repeat gene pairs of $V y R C H C s$ were also identified $[61,62]$. Further, the $\mathrm{Ka} / \mathrm{Ks}$ ratio between repetitive genes pairs can be used to infer the selection pressure in the process of genome evolution. Next, the MCScanX program (e-value: $1 \times 10^{-10}$, num alignments: 5) was used to detect the collinear region between $\mathrm{VvRCHCs}$ in grapevine and tomato/Arabidopsis; any collinear gene pair of $V v R C H C s$ was marked with red and green lines. The cis-elements were identified from the upstream 2-kb promoter sequences of the $V v R C H C s$ after submitting them to PlantCARE (http:// bioinformatics.psb.ugent.be/webtools/plantcare/html) [63], to obtain their image display, the resulting XML file was uploaded to TBtools [64].

\section{Expression analysis of $V y R C H C s$ in grapevine under drought stres}

To analyze the grapevine $R C H C$ genes' expression levels under drought stress, we obtained from the NCBI database (registration number: SRA110531) two different drought resistance genes (101.14 and M4) which were compared under two different treatments WS(Water Stress) and WW (Well-Watered) in roots and in different periods (T1-T4: 2d,4d、7d、10d) RNA-Seq data set [24]. Based on the expression values of RING $\mathrm{C} 3 \mathrm{H} 2 \mathrm{C} 3$ in the roots of the two genotypes, we calculated 
the $\log _{2}(\mathrm{WS} / \mathrm{WW})$ values (fold-change) in each time period (Table S4). The R package 'pheatmap' was used to produce a heatmap for this data.

\section{RNA extraction and quantitative real-time PCR (qRT-PCR)}

The qRT-PCR primers were designed using Primer Premier software (version 5.0). The RNA from Arabidopsis and grapevine (Vitis yeshanensis) leaves was extracted using the Spectrum Plant Total RNA Kit (SigmaAldrich, Beijing, China), after which reverse transcription of RNA into cDNA was done using the Prime Script RT Reagent Kit (Takara, Dalian, China). The qRT-PCR was performed in an $\mathrm{IQ}^{5}$ real-time PCR detection system (Bio-Rad Laboratories, Hercules, CA, USA) with SYBR Premium EX Taq II (Takara, Dalian, China). The reaction volume was $25 \mu \mathrm{l}$. The relative expression level corresponding to $\beta-T U B 4$ and ubiquitin 1 was calculated by using the $2^{-\Delta \Delta \mathrm{Ct}}$ method [65]; each reaction was prepared in triplicate and repeated three times. Primer sequence information in Table S1.

\section{E3 ubiquitin ligase activity assay}

The open reading frame (ORF) of $\mathrm{VyRCHC} 114$ and the different site mutants C320S, H341A, C328S, and N355A were separately cloned into the SalI/KpnI site of the pMAL-c5X vector (New England Biolabs UK Ltd, Hitchin, UK). According to the manufacturer's instructions, the pMAL protein fusion and purification system (New England Biolabs) was used to purify the fusion protein. Ubiquitination activity was then measured that according to the method described above [66], albeit with the following modifications made: $250 \mathrm{ng}$ of purified E3 (MBP-VyRCHC114, C320S, H341A, C328S, and $\mathrm{N} 355 \mathrm{~A})$ in the ubiquitination buffer $(50 \mathrm{mM}$ Tris- $\mathrm{HCl}$ ( $\mathrm{pH}$ 7.5), while the other reagents and steps used were the same. Primer sequence information in Table S1.

\section{Physiological analysis of drought stress response of transgenic Arabidopsis}

To determine the water loss rate, 10 leaves were detached from 3-week-old transgenic and WT plants and immediately weighed. The samples were then placed on dry filter paper at a relative humidity of $40-45 \%$ at room temperature and weighed over a time course. Leaves were sampled after dehydration to detect cell death, electrolyte leakage, malondialdehyde, antioxidant enzyme activity. The leaves collected before dehydration were used as a negative control.

For chlorophyll content measurements, approximately $0.05 \mathrm{~g}$ of fresh leaf material was placed in $5 \mathrm{ml}$ of $96 \%$ ethanol and incubated at $4 \mathrm{C}$ in the dark overnight. The absorbance of the extracted pigments was measured at 665 and $649 \mathrm{~nm}$ using a spectrophotometer (Hitachi
Limited, Tokyo, Japan) and the chlorophyll content was calculated as previously described [58].

Relative electrolyte leakage was measured as previously described [67], as was MDA content [66]. In addition, superoxide dismutase (SOD), peroxidase (POD), catalase (CAT), ascorbate peroxidase (APX) enzyme activities were extracted from $0.5 \mathrm{~g}$ leaves from abiotic stress treated plants as well as control plants, and measured as described by [68].

\section{Statistical analysis}

All the above experiments by SPSS software (version 21.0) were employed to analyze the statistically significant differences of the gene expression levels by ANOVA with Duncan's multiple range test. All experiments were repeated three times as independent analyses.

\section{Abbreviations}

RCHCs: RING C3H2C3-type genes; DEGs: Differentially expressed genes; qRTPCR: Quantitative real-time reverse transcription PCR; RNA-seq: RNAsequencing; WS: Water stress; WW: Well-watered; ML: Maximum likelihood; WT: Wild type; HMM: Hidden Markov Model

\section{Supplementary Information}

The online version contains supplementary material available at https://doi. org/10.1186/s12870-021-03162-8.

Additional file 1: Figure S1. Schematic diagram of $\mathrm{C} 3 \mathrm{H} 2 \mathrm{C} 3$ conserved sequence alignment of VvRCHCs. Cys $(\mathrm{C})$ and $\mathrm{His}(\mathrm{H})$ amino acids were added on a blue and pink background. The $\mathrm{C} 3 \mathrm{H} 2 \mathrm{C} 3$ conserved amino acid sequence length of these genes is shown later in the sequence.

Additional file 2: Figure S2. The original tree of Fig. 2.

Additional file 3: Figure S3. Number of introns in $V V R C H C S$.

Additional file 4: Figure S4. Analysis of Cis-acting elements in the VVRCHCS. a A list of V VRCHCS to facilitate correspondence. b Color-coded numbers of cis-acting elements of the three major types of $V V R C H C$ spromoters. c Different types of cis-actingelements are represented by different colored squares and their position on each VVRCHC gene promoter.

Additional file 5: Figure S5. Two model diagrams (VyRCHC114 is involved in drought resistance).

Additional file 6: Figure S6. $\mathrm{VyRCHC114} \mathrm{in} \mathrm{vitro} \mathrm{ubiquitin} \mathrm{gel}$ imprinting (uncut). Corresponding to the original image of gel imprinting in Fig.7A and B.

Additional file 7: Table S1. The sequences of the primers used in these experiments.

Additional file 8: Table S2. The distance between conserved metal ligands in the $\mathrm{C} 3 \mathrm{H} 2 \mathrm{H} 3$ domain of 143 VVRCHCS.

Additional file 9: Table S3. Functions of the cis-acting elements that found in the promoter region of each of VyRCHCs.

Additional file 10: Table S4. The number of VVRCHCs expressed in the roots of two different genotypes was expressed as $\log _{2}($ WS $/ W W$ ), and T1T4 represented different drought stress time.

\section{Acknowledgements}

We would like to thank all the colleagues in our laboratory for providing useful discussions and technical assistance.

Authors' contributions

Y.H.Y. and S.D.Y. conceived the original screening and research plans. S.D.Y. performed most of the experiments and finished the writing of the paper. D.L.G. participated in the modification of the paper L.B., K.K.Y., X.X.M. and 
G.H.Z. assisted in sorting out the data. W.R.X. and W.K.Y. provided guidance for experiments. Y.H.Y. and S.D.Y. wrote the article with contributions of all the authors. All authors read and approved the final manuscript.

\section{Funding}

This work was financially supported by grants from the Natural Science Foundation of China (no. NSFC:31701893 and U1504321), Zhongyuan Science and Technology Innovation Leaders (no. 194200510007), and Innovative Research Team in Henan University of Science \& Technology, China (no. 2015TTD003), and Program for Innovative Research Team (in Science and Technology) in University of Henan Province (21IRTSTHN021). The Funding bodies were not involved in the design of the study and collection, analysis, and interpretation of data and in writing the manuscript.

\section{Availability of data and materials}

All data generated and analyzed during this study are included in this published article. To identify the $\mathrm{C}_{3} \mathrm{H} 2 \mathrm{H} 3$ type of RING, the most recent grapevine genome file in the Ensembl Plants Database ( http://plants. ensembl.org/index.html ) was downloaded and used. Expression data of $\mathrm{C} 3 \mathrm{H} 2 \mathrm{H} 3$ type of RING genes in grapevine used in this study can be accessed via the NCBI SRA database with accession numbers of SRA110531. Figure S1 Schematic diagram of $\mathrm{C}_{3} \mathrm{H}_{2} \mathrm{C} 3$ conserved protein sequence alignment of VvRCHCs. Figure S2 The original tree of Fig. 2. Figure S3 Number of introns in $V V R C H C S$. Figure $S 4$ Analysis of cis-acting elements in the $V V R C H C s$. Figure S5. Two model diagrams (VyRCHC114 is involved in drought resistance). Figure S6 VyRCHC114 in vitro ubiquitin gel imprinting (uncut). Table S1 The sequences of the primers used in these experiments. Table S2 The distance between conserved metal ligands in the $\mathrm{C}_{3} \mathrm{H} 2 \mathrm{H} 3$ domain of 143 VvRCHCs. Table S3 Functions of the cis-acting elements that found in the promoter region of each of $V V R C H C S$. Table S4 Differential multiple expression matrix of VVRCHCs.

\section{Declarations}

Ethics approval and consent to participate

Not applicable.

\section{Consent for publication}

Not applicable.

\section{Competing interests}

The authors have no conflict of interest to report.

\section{Author details}

'College of Horticulture and Plant Protection, Henan University of Science and Technology, Luoyang 471023, Henan Province, China. ${ }^{2}$ Henan Engineering Technology Research Center of Quality Regulation and Controlling of Horticultural Plants, Luoyang 471023, Henan Province, China. ${ }^{3}$ School of Wine, Ningxia University, Yinchuan 750021, Ningxia Province, China.

Received: 5 August 2020 Accepted: 2 August 2021

Published online: 17 September 2021

\section{References}

1. Sadanandom A, Bailey M, Ewan R, Lee J, Nelis S. The ubiquitin-proteasome system: central modifier of plant signalling. New Phytol. 2012;196(1):13-28.

2. Sharma B, Joshi D, Yadav PK, Gupta AK, Bhatt TK. Role of ubiquitin-mediated degradation system in plant biology. Front Plant Sci. 2016;7:806.

3. Kelley DR. E3 ubiquitin ligases: key regulators of hormone signaling in plants. Mol Cell Proteomics. 2018;17(6):1047-54.

4. Stone SL. The role of ubiquitin and the $26 \mathrm{~S}$ proteasome in plant abiotic stress signaling. Front Plant Sci. 2014;5:135.

5. Shu K, Yang W. E3 ubiquitin ligases: ubiquitous actors in plant development and abiotic stress responses. Plant Cell Physiol. 2017;58(9):1461-76.

6. Qi S, Lin Q, Zhu H, Gao F, Zhang W, Hua X. The RING finger E3 ligase SpRing is a positive regulator of salt stress signaling in salt-tolerant wild tomato species. Plant Cell Physiol. 2016;57(3):528-39.

7. Zhang H, Cui F, Wu Y, Lou L, Liu L, Tian M, Ning Y, Shu K, Tang S, Xie Q. The RING finger ubiquitin E3 ligase SDIR1 targets SDIR1-INTERACTING PROTEIN1 for degradation to modulate the salt stress response and ABA signaling in Arabidopsis. Plant Cell. 2015;27(1):214-27.

8. Liu J, Zhang C, Wei C, Liu X, Wang M, Yu F, Xie Q, Tu J. The RING finger ubiquitin E3 ligase OsHTAS enhances heat tolerance by promoting $\mathrm{H}_{2} \mathrm{O} 2-$ induced stomatal closure in rice. Plant Physiol. 2016;170(1):429-43.

9. Ding S, Zhang B, Qin F. Arabidopsis RZFP34/CHYR1, a ubiquitin E3 ligase, regulates stomatal movement and drought tolerance via SnRK2. 6-mediated phosphorylation. Plant Cell. 2015;27(11):3228-44.

10. Lim CW, Baek W, Lee SC. The pepper RING-type E3 ligase CaAIRF1 regulates $A B A$ and drought signaling via CaADIP1 protein phosphatase degradation. Plant Physiol. 2017;173(4):2323-39.

11. Brugière N, Zhang W, Xu Q, Scolaro EJ, Lu C, Kahsay RY, Kise R, Trecker L, Williams RW, Hakimi S. Overexpression of RING domain E3 ligase ZmXerico1 confers drought tolerance through regulation of ABA homeostasis. Plant Physiol. 2017;175(3):1350-69.

12. Ryu MY, Cho SK, Kim WT. The Arabidopsis C3H2C3-type RING E3 ubiquitin ligase AtAIRP1 is a positive regulator of an abscisic acid-dependent response to drought stress. Plant Physiol. 2010;154(4):1983-97.

13. Cho SK, Ryu MY, Seo DH, Kang BG, Kim WT. The Arabidopsis RING E3 ubiquitin ligase AtAIRP2 plays combinatory roles with AtAIRP1 in abscisic acid-mediated drought stress responses. Plant Physiol. 2011;157(4):2240-57.

14. Kim JH, Kim WT. The Arabidopsis RING E3 ubiquitin ligase AtAIRP3/LOG2 participates in positive regulation of high-salt and drought stress responses. Plant Physiol. 2013;162(3):1733-49.

15. Park C, Lim CW, Baek W, Lee SC. RING type E3 ligase CaAIR1 in pepper acts in the regulation of $A B A$ signaling and drought stress response. Plant Cell Physiol. 2015;56(9):1808-19.

16. Yu Y, Bian L, Yu K, Yang S, Zhang G, Guo D. Grape (Vitis davidii) VdGATA2 functions as a transcription activator and enhances powdery mildew resistance via the active oxygen species pathway. Sci Hortic. 2020;267: 109327.

17. Wang M, Vannozzi A, Wang G, Liang Y-H, Tornielli GB, Zenoni S, Cavallini E, Pezzotti M, Cheng Z-MM. Genome and transcriptome analysis of the grapevine (Vitis vinifera L.) WRKY gene family. Hortic Res. 2014;1:14016.

18. Hardie WJ, Considine JA. Response of grapes to water-deficit stress in particular stages of development. Am J Enol Viticult. 1976;27(2):55-61.

19. dos Santos TP, Lopes CM, Rodrigues ML, de Souza CR, Maroco JP, Pereira JS, Silva JR, Chaves MM. Partial rootzone drying: effects on growth and fruit quality of field-grown grapevines (Vitis vinifera). Funct Plant Biol. 2003;30(6): $663-71$.

20. Chaves MM, Flexas J, Pinheiro C. Photosynthesis under drought and salt stress: regulation mechanisms from whole plant to cell. Ann bot. 2009; 103(4):551-60.

21. Liu J, Zhao F, Guo Y, Fan X, Wang Y, Wen Y. The ABA receptor-like gene VyPYL9 from drought-resistance wild grapevine confers drought tolerance and ABA hypersensitivity in Arabidopsis. Plant Cell Tiss Org. 2019;138(3):54358.

22. Yang Y, He M, Zhu Z, Li S, Xu Y, Zhang C, Singer SD, Wang Y. Identification of the dehydrin gene family from grapevine species and analysis of their responsiveness to various forms of abiotic and biotic stress. BMC Plant Biol. 2012;12(1):140.

23. Jing Z, Wang X. Genetic relationship between Chinese wild Vitis species and American and European cultivars based on ISSR markers. Biochem Syst Ecol. 2013;46:120-6.

24. Corso M, Vannozzi A, Maza E, Vitulo N, Meggio F, Pitacco A, Telatin A, D'Angelo M, Feltrin E, Negri AS, et al. Comprehensive transcript profiling of two grapevine rootstock genotypes contrasting in drought susceptibility links the phenylpropanoid pathway to enhanced tolerance. J Exp Bot. 2015; 66(19):5739-52.

25. Li Y, Wu B, Yu Y, Yang G, Wu C, Zheng C. Genome-wide analysis of the RING finger gene family in apple. Mol Genet Genomics. 2011;286(1):81.

26. Yang L, Miao M, Lyu H, Cao X, Li J, Li Y, Li Z, Chang W. Genome-wide identification, evolution, and expression analysis of RING finger gene family in solanum lycopersicum. Int J Mol Sci. 2019;20(19):4864.

27. Qanmber G, Yu D, Li J, Wang L, Ma S, Lu L, Yang Z, Li F. Genome-wide identification and expression analysis of Gossypium RING-H2 finger E3 ligase genes revealed their roles in fiber development, and phytohormone and abiotic stress responses. J Cot Res. 2018;1(1):1-17.

28. Alam I, Yang YQ, Wang Y, Zhu ML, Wang HB, Chalhoub B, Lu YH. Genomewide identification, evolution and expression analysis of RING finger protein genes in Brassica rapa. Sci Rep. 2017;7:40690. 
29. Hua Z, Vierstra RD. The cullin-RING ubiquitin-protein ligases. Annu Rev Plant Biol. 2011;62:299-334.

30. Jaillon O, Aury J, Noel B, Policriti A, Clepet C, Casagrande A, Choisne N, Aubourg S, Vitulo N, Jubin C. The grapevine genome sequence suggests ancestral hexaploidization in major angiosperm phyla. Nature. 2007; 449(7161):463.

31. Consortium TG. The tomato genome sequence provides insights into fleshy fruit evolution. Nature. 2012:485(7400):635.

32. Serrano M, Parra S, Alcaraz LD, Guzmán P. The ATL gene family from Arabidopsis thaliana and Oryza sativa comprises a large number of putative ubiquitin ligases of the RING-H2 type. J Mol Evol. 2006;62(4):434-45.

33. Ren R, Wang H, Guo C, Zhang N, Zeng L, Chen Y, Ma H, Qi J. Widespread whole genome duplications contribute to genome complexity and species diversity in angiosperms. Mol Plant. 2018;11(3):414-28.

34. Moore RC, Purugganan MD. The early stages of duplicate gene evolution. Proc Nat Acad Sci USA. 2003;100(26):15682-7.

35. Wang N, Liu Y, Cong Y, Wang T, Zhong X, Yang S, Li Y, Gai J. Genome-wide identification of soybean U-Box E3 ubiquitin ligases and roles of GmPUB8 in negative regulation of drought stress response in Arabidopsis. Plant Cell Physiol. 2016;57(6):1189-209.

36. Cannon SB, Mitra A, Baumgarten A, Young ND, May G. The roles of segmental and tandem gene duplication in the evolution of large gene families in Arabidopsis thaliana. BMC Plant Biol. 2004;4(1):10.

37. Li Z, Hua X, Zhong W, Yuan Y, Wang Y, Wang Z, Ming R, Zhang J. Genomewide identification and expression profile analysis of WRKY family genes in the autopolyploid saccharum spontaneum. Plant Cell Physiol. 2019;61(3): 616-30.

38. Park J, Nguyen KT, Park E, Jeon J-S, Choi G. DELLA proteins and their interacting RING finger proteins repress gibberellin responses by binding to the promoters of a subset of gibberellin-responsive genes in Arabidopsis. Plant Cell. 2013;25(3):927-43.

39. Zhang Y, Yang C, Li Y, Zheng N, Chen H, Zhao Q, Gao T, Guo H, Xie Q. SDIR1 is a RING finger E3 ligase that positively regulates stress-responsive abscisic acid signaling in Arabidopsis. Plant Cell. 2007;19(6):1912-29.

40. Meng XB, Zhao WS, Lin RM, Wang M, Peng YL. Molecular cloning and characterization of a rice blast-inducible RING-H2 type zinc finger gene: full length research paper. DNA Seq. 2006;17(1):41-8.

41. Li WL, Sun Q, Li WC, Yu YL, Zhao M. Meng ZD: Characterization and expression analysis of a novel RING-HC gene, ZmRHCP1, involved in brace root development and abiotic stress responses in maize. J Integr Agr. 2017; 16(9):1892-9.

42. Ju HW, Min JH, Chung MS, Kim CS. The atrzf1 mutation of the novel RING type E3 ubiquitin ligase increases proline contents and enhances drought tolerance in Arabidopsis. Plant Sci. 2013;203:1-7.

43. Li M, Li Y, Zhao J, Liu H, Jia S, Li J, Zhao H, Han S, Wang Y. GpDSR7, a novel E3 Ubiquitin ligase gene in Grimmia pilifera is involved in tolerance to drought stress in Arabidopsis. PloS One. 2016;11(5):e0155455.

44. Ji XR, Yu YH, Ni PY, Zhang GH, Guo DL. Genome-wide identification of small heat-shock protein (HSP20) gene family in grape and expression profile during berry development. BMC Plant Biol. 2019;19(1):433

45. Shanks CM, Hecker A, Cheng CY, Brand L, Collani S, Schmid M, Schaller GE, Wanke D, Harter K, Kieber JJ. Role of BASIC PENTACYSTEINE transcription factors in a subset of cytokinin signaling responses. Plant J. 2018;95(3):45873.

46. Lian H, Wang L, Ma N, Zhou CM, Han L, Zhang TQ, Wang JW. Redundant and specific roles of individual MIR172 genes in plant development. PLoS Biol. 2021;19(2):e3001044.

47. Ewan R, Pangestuti R, Thornber S, Craig A, Carr C, O'Donnell L, Zhang C, Sadanandom A. Deubiquitinating enzymes AtUBP12 and AtUBP13 and their tobacco homologue NtUBP12 are negative regulators of plant immunity. New Phytol. 2011;191(1):92-106.

48. Cui X, Lu F, Li Y, Xue Y, Kang Y, Zhang S, Qiu Q, Cui X, Zheng S, Liu B, Xu X, Cao X. Ubiquitin-specific proteases UBP12 and UBP13 act in circadian clock and photoperiodic flowering regulation in Arabidopsis. Plant Physiol. 2013; 162(2):897-906.

49. Ding A, Tang $X$, Yang D, Wang M, Ren A, Xu Z, Hu R, Zhou G, O'Neill M Kong Y. ERF4 and MYB52 transcription factors play antagonistic roles in regulating homogalacturonan de-methylesterification in Arabidopsis seed coat mucilage. Plant Cell. 2021;33(2):381-403.

50. Teng K, Li J, Liu L, Han Y, Du Y, Zhang J, Sun H, Zhao Q. Exogenous ABA induces drought tolerance in upland rice: the role of chloroplast and ABA biosynthesis-related gene expression on photosystem II during PEG stress. Acta physiol plant. 2014;36(8):2219-27.

51. Apel K, Hirt H. Reactive oxygen species: metabolism, oxidative stress, and signal transduction. Annu Rev Plant Biol. 2004;55:373-99.

52. Park JJ, Yi J, Yoon J, Cho LH, Ping J, Jeong HJ, Cho SK, Kim WT, An G. OsPUB15, an E3 ubiquitin ligase, functions to reduce cellular oxidative stress during seedling establishment. Plant J. 2011;65(2):194-205.

53. Liu J, Xia Z, Wang M, Zhang X, Yang T, Wu J. Overexpression of a maize E3 ubiquitin ligase gene enhances drought tolerance through regulating stomatal aperture and antioxidant system in transgenic tobacco. Plant Physiol Biochem. 2013;73:114-20.

54. Le Hir R, Castelain M, Chakraborti D, Moritz T, Dinant S, Bellini C. At bHLH68 transcription factor contributes to the regulation of $\mathrm{ABA}$ homeostasis and drought stress tolerance in Arabidopsis thaliana. Physiol Plant. 2017;160(3): 312-27.

55. Hsieh T, Li C, Su R, Cheng C, Tsai Y, Chan M. A tomato bZIP transcription factor, SIAREB, is involved in water deficit and salt stress response. Planta. 2010;231(6):1459-73.

56. Yu D, Zhang L, Zhao K, Niu R, Zhai H, Zhang J. VaERD15, a transcription factor gene associated with cold-tolerance in Chinese Wild Vitis amurensis. Front Plant Sci. 2017;8:297.

57. Ma L, Li Y, Chen Y, Li X. Improved drought and salt tolerance of Arabidopsis thaliana by ectopic expression of a cotton (Gossypium hirsutum) CBF gene. Plant Cell Tiss Org. 2015;124(3):583-98.

58. Hou H, Jia H, Yan Q, Wang X. Overexpression of a SBP-Box Gene (VpSBP16) from Chinese wild vitis species in Arabidopsis improves salinity and drought stress tolerance. Int J Mol Sci. 2018;19(4):940.

59. Yu Y, Bian L, Yu K, Yang S, Zhang G, Guo D. Grape (Vitis davidii) VdGATA2 functions as a transcription activator and enhances powdery mildew resistance via the active oxygen species pathway. Sci Hortic. 2020;267: 109327

60. Guo R, Qiao H, Zhao J, Wang X, Tu M, Guo C, Wan R, Li Z, Wang X. The grape VIWRKY3 gene promotes abiotic and biotic stress tolerance in transgenic Arabidopsis thaliana. Front Plant Sci. 2018;9:545.

61. Moore RC, Purugganan MD. The early stages of duplicate gene evolution. Proc Nat Acad Sci U S A. 2003;100(26):15682-7.

62. Ni P, Ji X, Guo D. Genome-wide identification, characterization, and expression analysis of GDSL-type esterases/lipases gene family in relation to grape berry ripening. Sci Hortic. 2020;264:109162.

63. Lescot $M$, Déhais $P$, Thijs $G$, Marchal $K$, Moreau $Y$, Van de Peer $Y$, Rouzé $P$, Rombauts S. PlantCARE, a database of plant cis-acting regulatory elements and a portal to tools for in silico analysis of promoter sequences. Nucleic Acids Res. 2002;30(1):325-7.

64. Chen $\mathrm{C}$, Chen $\mathrm{H}$, Zhang $Y$, Thomas H, Frank M, He Y, Xia R. TBtools - an integrative toolkit developed for interactive analyses of big biological data. Mol Plant. 2020;13(8):1194-202.

65. Livak KJ, Schmittgen T. Analysis of relative gene expression data using realtime quantitative PCR and the 2(-Delta Delta C(T)) Method. Methods. 2001; 25(4):402-8

66. Yu Y, Xu W, Wang J, Wang L, Yao W, Yang Y, Xu Y, Ma F, Du Y, Wang Y. The Chinese wild grapevine (Vitis pseudoreticulata) E3 ubiquitin ligase Erysiphe necator-induced RING finger protein 1 (EIRP1) activates plant defense responses by inducing proteolysis of the VpWRKY11 transcription factor. New Phytol. 2013;200(3):834-46.

67. Zhang L, Zhao G, Xia C, Jia J, Liu X, Kong X. A wheat R2R3-MYB gene, TaMYB30-B, improves drought stress tolerance in transgenic Arabidopsis. J Exp Bot. 2012;63(16):5873-85.

68. Chen R, Wu P, Cao D, Tian H, Chen C, Zhu B. Edible coatings inhibit the postharvest berry abscission of table grapes caused by sulfur dioxide during storage. Postharvest Biol Tec. 2019;152:1-8.

\section{Publisher's Note}

Springer Nature remains neutral with regard to jurisdictional claims in published maps and institutional affiliations. 